\title{
الموارد المائية البديلة في هقول جنوب العراق
}

\section{عبدلامت تركيشنالة

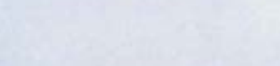

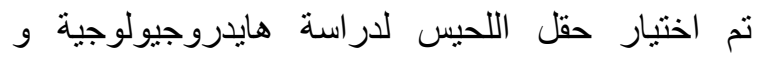
هايدروجيوكيميائية المياه الجوفية في تكوين الطيارات الذي لائي يمثل أعلى وحده طباقية ممثلة للعصر الكريتاسي .... بسبب التباه حدوث هذه الظاهره (تدفق الماء) في معظم ابار الحثلة الحقل

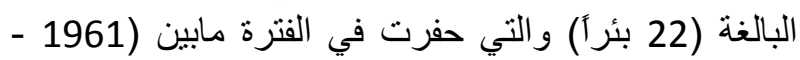
1990) و وجود بعض المعلومات لبعض التحاليل الفيزيائية

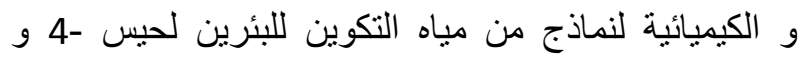
لحيس - 6 التي اجريت في قسم المختبرات المركزية في

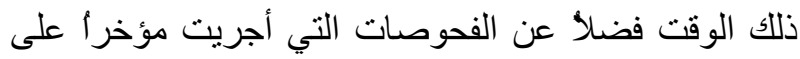

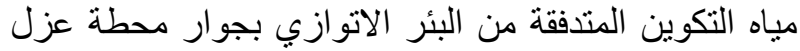
اللحيس في قسم المختبرات المركزية ومختبرات الاتئر الطاقة الكهربائية في النجيبية.

تتو اجد المياه الجوفية في تكوين الطيار ات ـ حقل اللحيس في

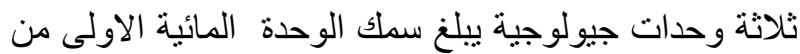

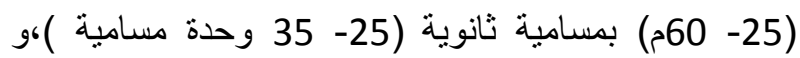

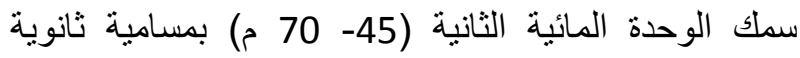
(20- 30 وحدة مسامية ) ، أما أكبر سمك فيكون في الوحدة المدة المائية الثالثة حيث يصل الى (120- 120 150م) وبسامية ثانوية الماية اقل (10- 20 وحدة مسامية). علمأ بان المساميه الكليه المسجله بواسطة مجس النيوترون مسجله في البئر لحيس 6

كميات المياه الجوفية في التكوين هائلة جداً ، يؤيدها السمك

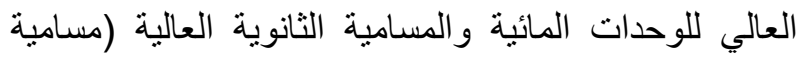

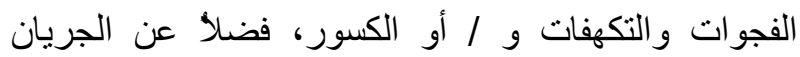

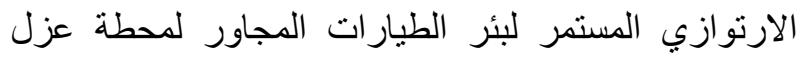

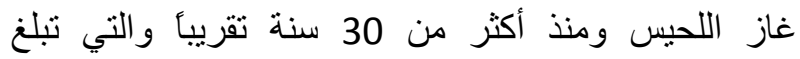
انتاجيته حاليأ حو الي 596 م3 / يو م.

كما أنه سوف يتم طرح ثناثة مشاريع اخرى بعد نوفر أجهزة

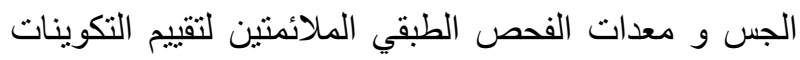
الحاملة للمباه الحوفية في التجويف المفتوح ح.
ان العراق باعتباره دولة مصب يتاثر تأثراُ بالغأ

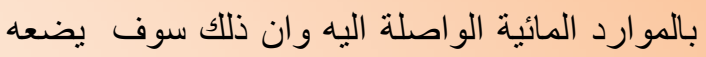

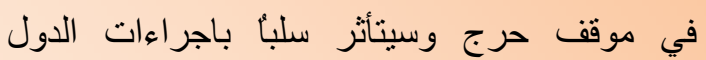

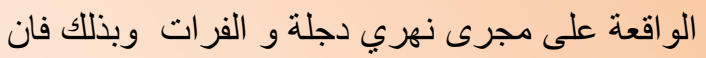

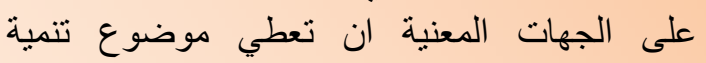
الموارد المائية والمحافظة عليها الأولوية القصوى العية تلفية

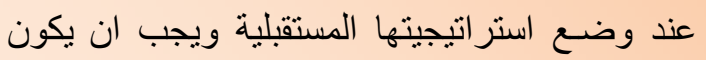

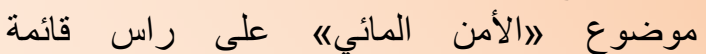

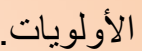

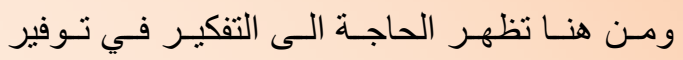
مصادر اخرى للمياه كموارد مائية أستر اتيجية تسند

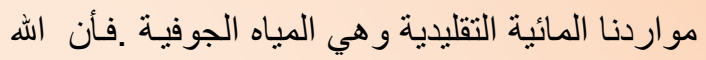

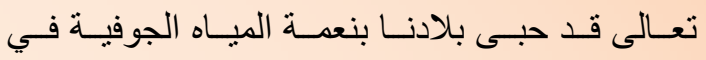

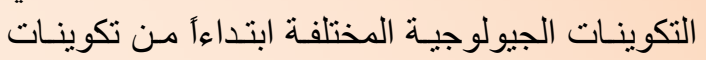

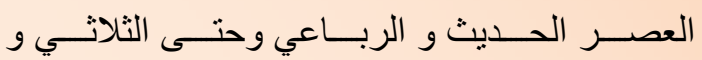

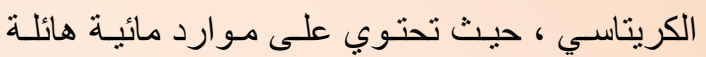

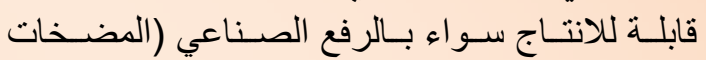

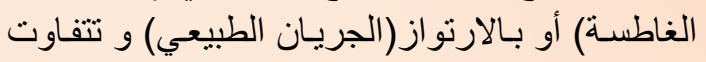

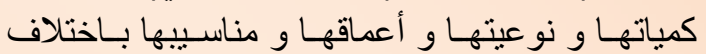
طبيعة التكوينات الجيولوجية التي تحويها.

وشهدت السنوات الاخيرة خطط انفجارية نتيجة التقام

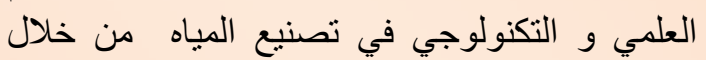

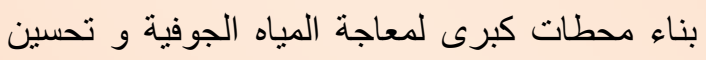

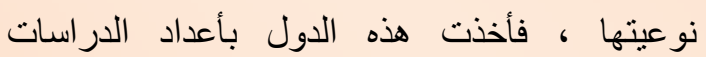
الهايدرولوجية و و الجيوفيزيائية و و الجيوكيميائية للانظمة الهايدروجيولوجية الجية الجوفية وتقيبيم مصادر هائية

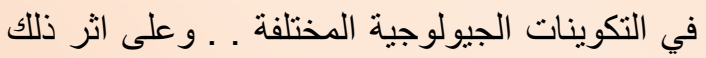

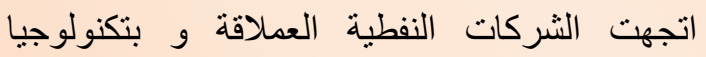
معالجة راقية بانتاج المياه المكمنية المصاحبة للنفوط

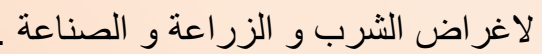




\section{ALTERNATIVE WATER RESOURCES IN SOUTHERN OIL FIELDS \\ ABSTRACT}

Demand of ground water for agriculture, drinking water and industrial purposes is increasing with the increase in population and consequently as a result of that, we should explore and exploit the non-conventional water resources for supporting our conventional one, especially Iraq today suffer from and go through with a factual crisis of water release.

The main objective of the project is exploitation of ground water of Tayarat (upper cretaceous) formation for industrial proposes in our southern oil fields, so we have been elected "Luhais Field" because the natural water flowing phenomena was clear in the most of the wells in this field where drilled since $(1961$ - 1990) for oil production from $\mathrm{Nahr} \mathrm{Umr}$ and Zubair reservoirs.

Few of old available analyses (chemical \& physical) of water sample of Luhais- $4 \& 6$ as well as the Luhais Artesian well ( 30 years old) next to Luhais degassing station is facilitated the physical - chemical sampling and analysis may be a primary evaluation of formation water for different industrial processes.

Ground water of Tayarat formation is distributed over three geological units composed of Limestone, Dolomite, shale and Anhydrite with different ratios. The first one has $(25-60 \mathrm{~m})$ thickness with (25 -30 p.u) secondary porosity, the second unit has $(45-70 \mathrm{~m})$ thickness with (20 - 30 p.u) secondary porosity, whereas third unit recognizes the highest thickness where reaches to $(120-150 \mathrm{~m})$ and secondary porosity (10 - 20 p.u).

The quantity of artesian ground water in the artesian well closed to Luhais degasen station is reached to (594 m3/day) according to the last measure of productivity.

The quality of ground water of this formation is good except high concentration of sulfate and $\mathrm{H}_{2} \mathrm{~S}$ and the other properties need some treatment.

We recommend constructing a complete central water station in the field to use it for different industrial processes.

$$
\begin{aligned}
& \text { 1- استغلال المياه الجوفية لتكوين ام رضومة }
\end{aligned}
$$

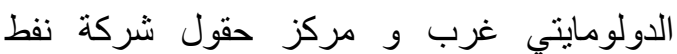

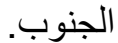

2- استغلال المياه الجوفية لتكوين الغار الرملي مركز حقول شركة نفط الجنوب.

3- استغلال المياه الجوفية لتكوين الدمام (تحويل

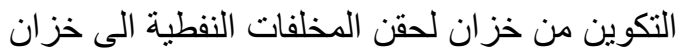

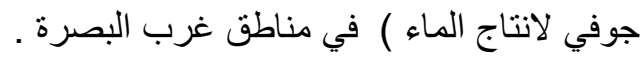
و وعدئذ يجب الثروع بتقبيم التكوينات اعلاه في وقت واحد خلال عمليات الحفر الحالية و المستقبلية

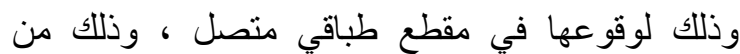

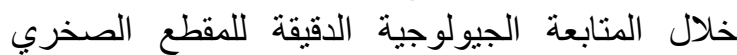

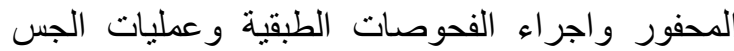

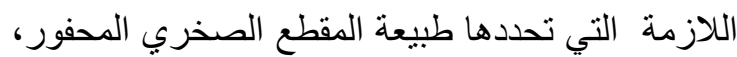

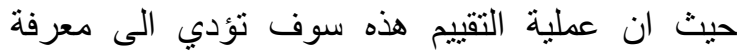

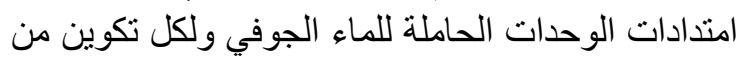
التكوينات المقيمة ومعرفة مواصفات مياهيا وكميات الانتاج وبذللك تكتمل صورة التقييم . 
مثيلاته و مكافئاته في الكويت لكنها غير واضحة في السعودية حيث ان السحنات تتغير بأتجاه المنطقه الغربية (حقول عبيد ابوخيمة - صفوي) الى الصخور الكلسية الطينية تتخلاها طبقات السجيل و المارل شكل (1). ويميل التكوين طباقيا" و و تركيبيا" بأتجاه جنوب و جنوبل

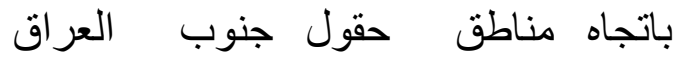
شكل (2) ليكؤن احدث وحدة طباقية تابعة الى العصر الكريتاسي تتكون من تعاقب

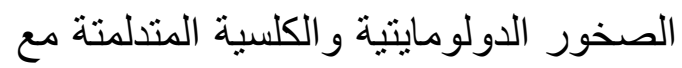
الانهايدرايت وروبود السجيل القيري المتفحم Bituminous shale في اعلى التكوين.

\section{1- جيولوجية تكوين الطيارات} يظهر المقطع المثال للتكوين في منكثف صحر اوي قرب جبل طيار ات على الى فئ في بعد (21 ميل) من مدينة الرطبة غربي مئرب

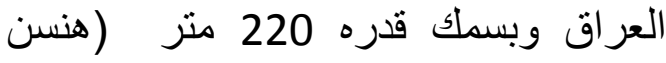
،1948 ) ويتكون في الغالب من صخور الدولومايت Dolomite و الصخور الكلسية

Limestone Dolomitic المتدلمتنة وأختير أعلى التكوين مع بداية ظلئه

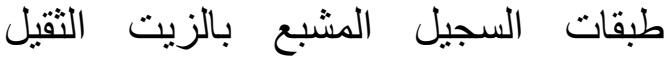
(البتيومين) يحده من الاعلى وبشكل غير

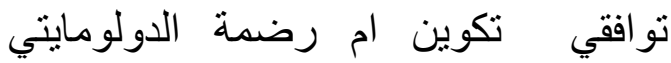
الثلاثي ومن الاسفل تكوين الثيرانش المارلي العميق و يختفي التكوين بأتجاه حقول ميسان و ايران و ذو مظاهاة جيدة مع العياه

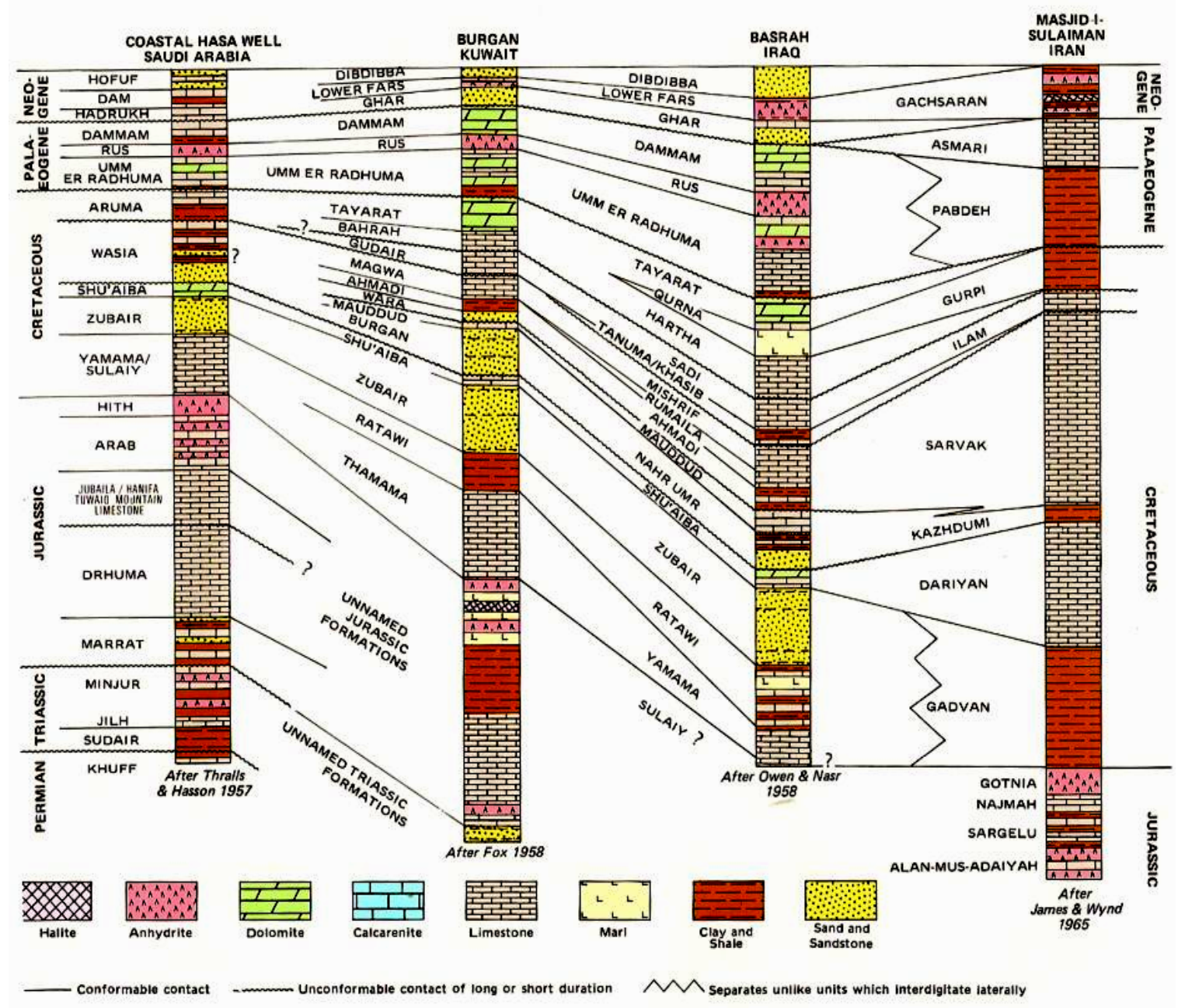

$$
\text { شكل (1 ) المظاهاة الاقليمية للعمود الطباقي في جنوب العراق نقلا" عن Arabian American Oil Company.1975) }
$$


ومن خلال الانعكاسات السحنية للتكوين تظهر بيئة الترسيب قريبة من البيئة البحرية الضحلة او النرتية shallow neritic marine lenvironment العصر الكريتاسي (خلال الماسترختي) وعند بداية الارتفاع الاقليمي لحوض الترسيب الذي سبب في انقطاع عملية

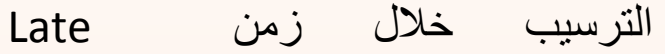
( Mastrichtian-Early Paleocene .Fuloria,1976) بيلغ سمك التكوين (150-400 مثر) في حقول الرميلة و الزبير و اللحيس والصبة و الرطاوي ،ويزداد ايضـا في حقلي ابو خيمة و خضر الماء (350413 منر) لكنه يقل في باقي الحقول الغربية (شاوية- عبيد- صغوي) ليصبح سمكه (180-120 متر). أما في حقل اللحيس (منطقة الدراسة) شكل (3) و (4)، فحفرت منذ العام 1961 ولغاية عام 1990 (22) بئر أنطيًا بهدف الانتاج من مكمني نهر عمر و الزبير جدول (1).

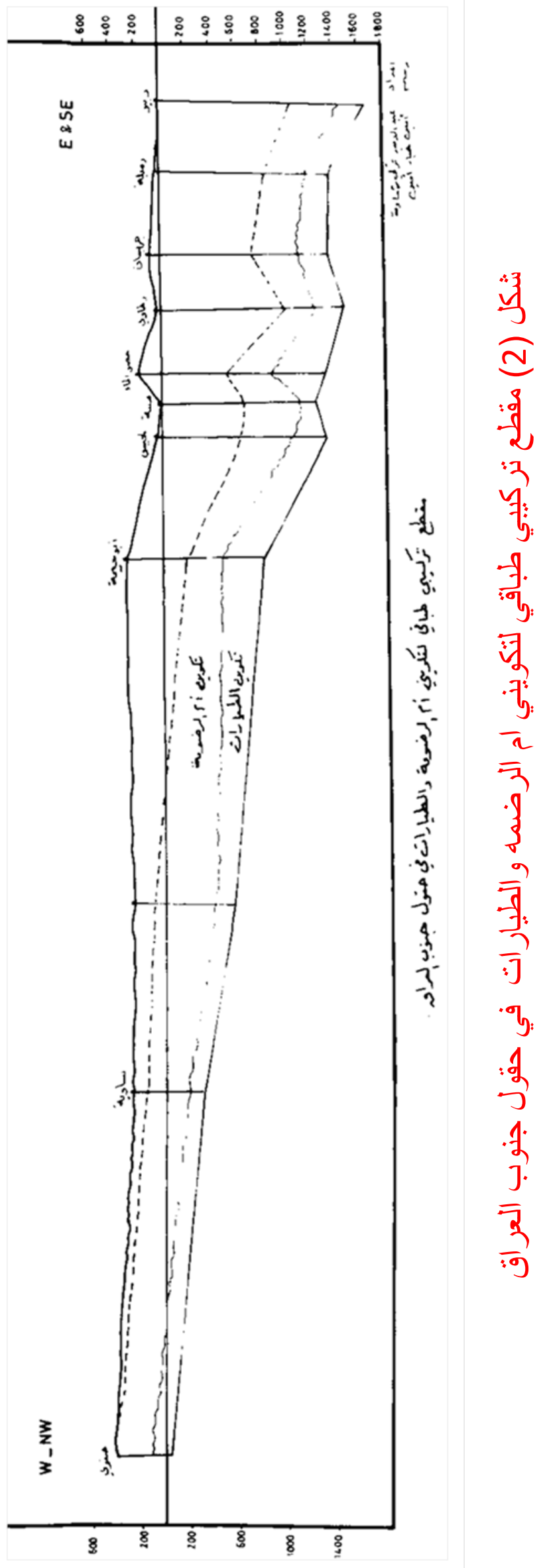


جدول (1) أعماق و سماكات تكوين الطيارات في حقل اللحيس

\begin{tabular}{|c|c|c|c|c|c|c|}
\hline البئر البر & 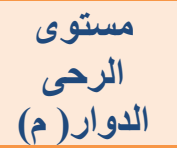 & سنة & أعلى التكوين ( م) & السمك ( م) & جريان الماء & تحاليل الماء \\
\hline Lu -1 & 66.69 & 1961 & 1105.8 & 272 & & لا يوجد \\
\hline Lu - 2 & 69.2 & 1972 & 1118.6 & 265.4 & يوجد & لا يوجد \\
\hline Lu - 3 & 63.55 & 1972 & 1098 & 267.5 & يوجد & ل لا يوجد \\
\hline Lu - 4 & 67.8 & 1974 & 1151 & 242 & يوجد & يوجل \\
\hline Lu - 5 & 64.28 & 1974 & 1098.5 & 265 & - & لا يوجد \\
\hline Lu - 6 & 73.10 & 1975 & 1139 & 253 & يوجد & يوجد \\
\hline Lu - 7 & 69.75 & 1975 & 1133.4 & 216.6 & يوجد & لا لايوجد \\
\hline Lu - 8 & 61.7 & 1978 & 1109.8 & 242 & يوجد & لا لايوجد \\
\hline Lu - 9 & 60.14 & 1975 & 1087.5 & 240 & وجد & لا لا يوجد \\
\hline Lu - 10 & 74.77 & 1975 & 1133.4 & 259 & يوجد & لا لا يوجد \\
\hline Lu - 11 & 67.86 & 1976 & 1115.7 & 253 & $?$ & لا يوجد \\
\hline Lu - 12 & 64.86 & 1976 & 1103 & 272 & $?$ & لا لا يوجد \\
\hline Lu - 13 & 65.38 & 1978 & 1118.8 & 252 & $?$ & لا لا يوجد \\
\hline Lu - 14 & 72.05 & 1978 & 1128.6 & 240 & $?$ & لا لا يوجد \\
\hline Lu - 15 & 66.5 & 1979 & 1118.8 & 252 & لا يوجد & لا لا يوجد \\
\hline Lu - 16 & 68.7 & 1979 & 1117 & 254 & لا لايوجد & ل لا يوجد \\
\hline Lu - 17 & 65.4 & 1979 & 1001.6 & 327 & لا لاوجد & لا يوجد \\
\hline Lu-18 & 64.2 & 1979 & 1118 & 262 & لا يوجد & لا يوجد \\
\hline Lu-19 & 63.2 & 1979 & 1112 & 222 & يوجد & لا يوجد \\
\hline Lu - 20 & 71.2 & 1980 & 1121 & 265 & لا يوجد & لا يوجد \\
\hline Lu - 21 & 73.9 & 1986 & 1129 & 246 & يوجد & لا يوجد \\
\hline Lu - 22 & 72.4 & 1990 & 1112 & 257 & $?$ & لا يوجد \\
\hline
\end{tabular}

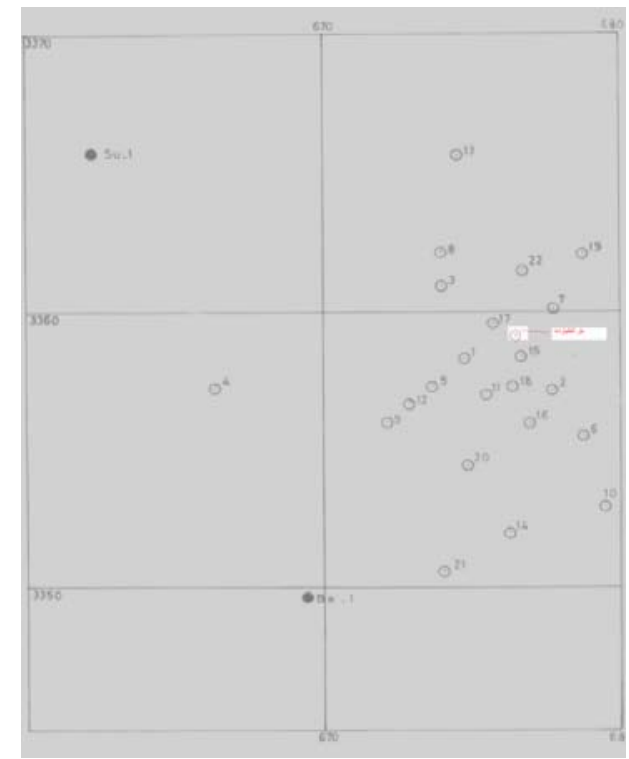

شكل(4) مو اقع ابار حقل اللحيس

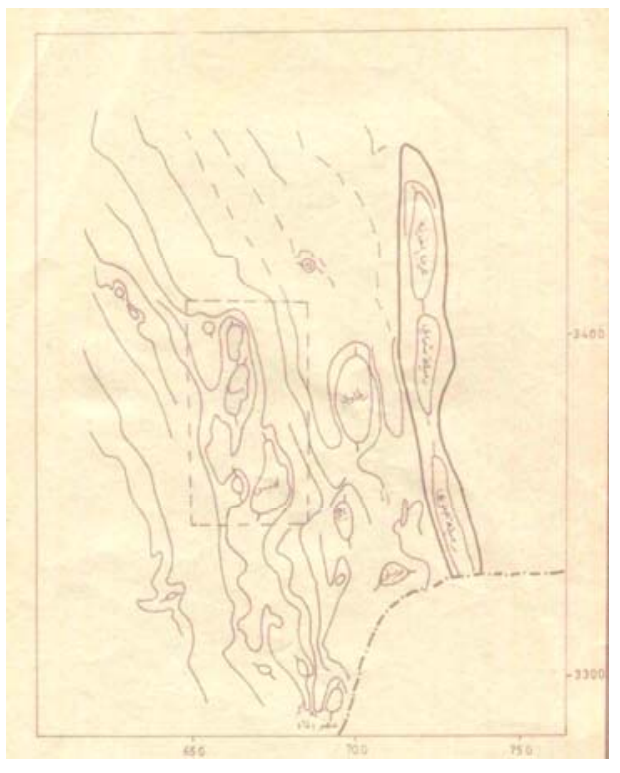

شكل(3) موقع حقل اللحيس نسبة

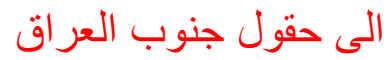


توضح الخارطة التركيبية structure contour map لأعلى التكوين في الحقل شكل فئل

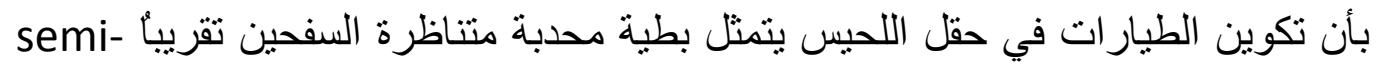
symmetrical anticline

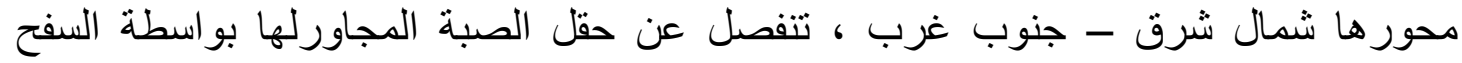

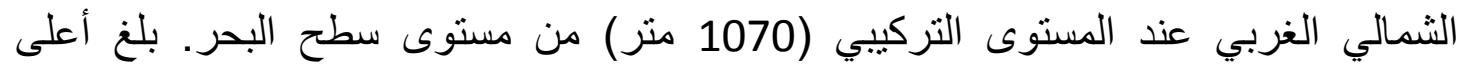

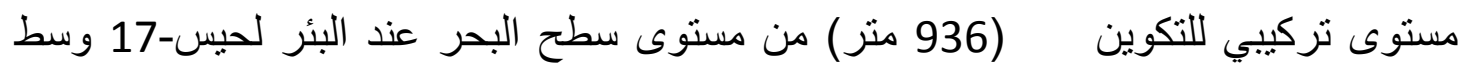

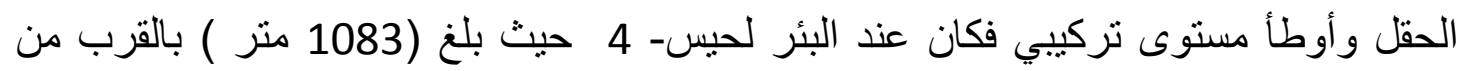
نهاية الغاطس الجنوبي الغربي،و توضح ناون خارطة السماكة isopach map بأن أكبر سمك للتكوين بلغ (327 منر ) عند البئر لحيس- 17 وسط الحقل ويقل بجميع اتجاهات الحقل ليصل الئل

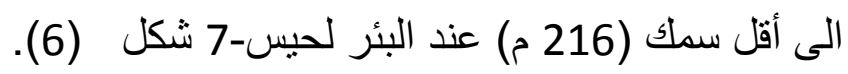
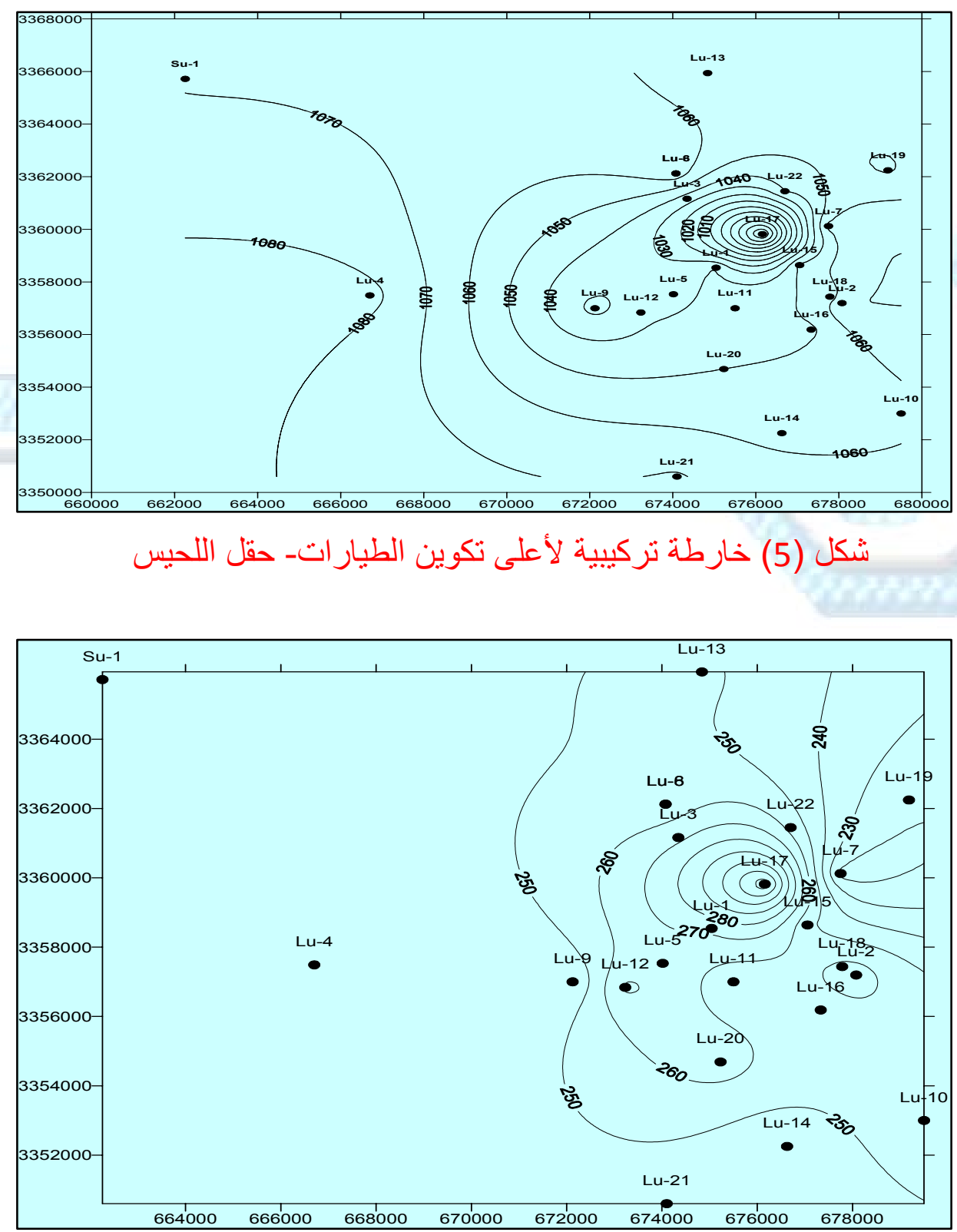

شكل (6) خارطة السماكة لتكوين الطيار ات - حقل اللحيس 
يتفق أكثر الباحثين على الاصل التحويري للدولومايت حيث يتكون بتاثير التين

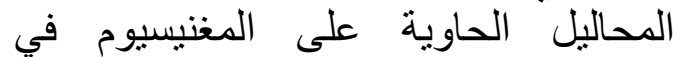
الصخور الجيرية Limestone المترسبة اوليا"(Fochtbauer,1974) ) وتحدث على مرحلتين - مبكرة حيث تحصل عملية احلال للرغوة الجيرية micrite المترسبة

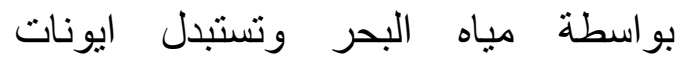
الكاسيوم بايونات المغنيسيوم و عندما ينفصل البحر عن الرواسب تحصل المرنات المبلة الثانية ويكون مصدر ايونات المغنيسيوم هنا و

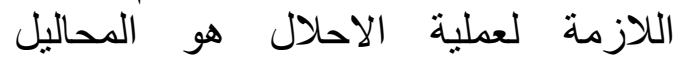
المسامية Pore Fluids الغنية بالمغنيسيوم و المنواجدة في مسام الصخور ويعزى اليها تلف النسيج الصخري (Tocker,1983 ) اي تكون المسامات الكبيرة و الفجوات و التكهات و التي تصبح لاحقاُ مستقبلات

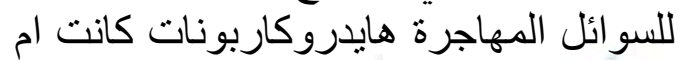
مياه شكل (7 ). تتعاقب الصخور الدولومايتية في تكوين الطيارات مع الصخور الكلسية و الكلسية

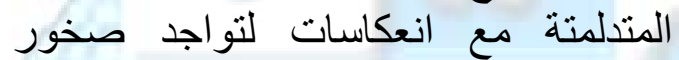

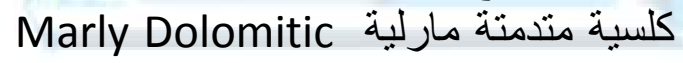

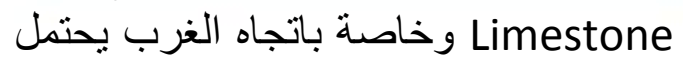
أن تكون قد ترسبت من مياه بحرية ذات بات ملوحة واطئة (الجوزي، 1976 ل
1-1 الالولهر الحيولوحية في تكمن |لس

Black 1-1-1 السـجيل الاسود المترقرق Bituminous Fissile Shale تتواجد في اعلى التكوين طبقات رقيقة من السجيل الاسود المتفحم او القيري Bituminous و الذي يؤخذ على اساسه قمة التكوين في معضم حقول جنوب العراق

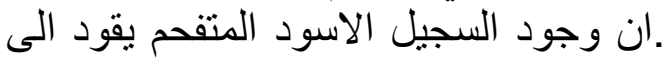

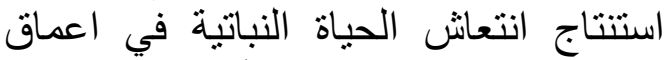

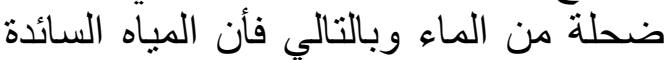
هي دن نوع العذبة او المجة المختلة المنة Fresh or Brakish water صفات المياه البحرية المالحةهويدعم هذا لإنات Flora الاستنتاج تواجد القطع النباتية المتمثلة بأنسجة و اوراق النباتات و تو اجد قطع العنبر Fragments Amber في في وت وني هذا الجزء من التكوين كما ان وجود بعض

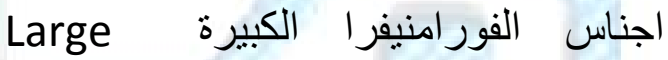
Foraminifera في بيئة نرنية ضحلة العمق ( الجوزي 1976

Dolomitization 2-1-1 الدلمتة)

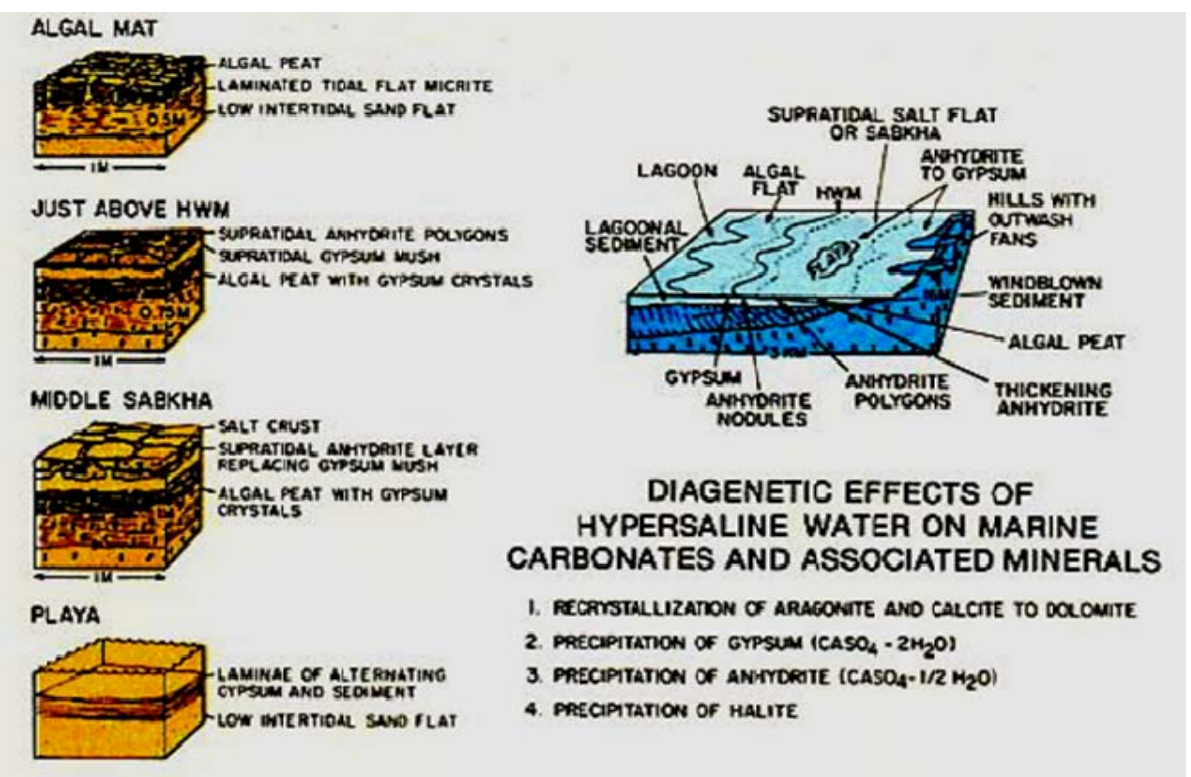
c نة ت الدلمت كل (7) - (7) عملي 


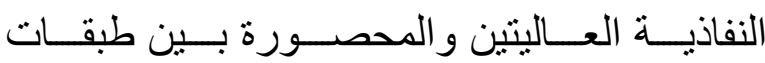

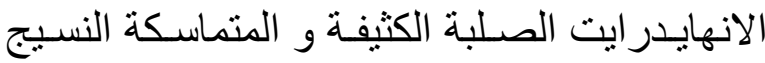

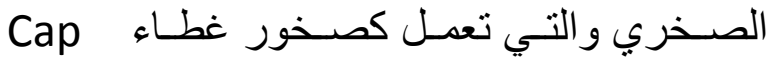

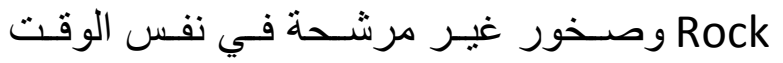

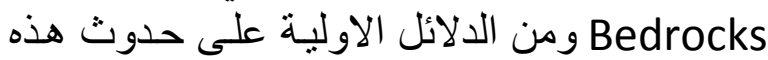

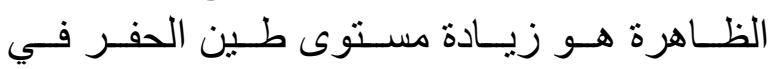

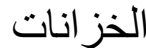
وزيادة مفاجئة في معدل سرعة الحفر و انخفاض وزن الانابيب وبذللك تنخفض كثافة طين الحفر نتيجة تلوثنه بالماء الجوفي .

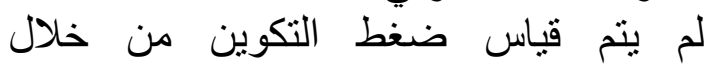
فحوصات طبقية او انتاجية وان تصور اتنا للتنبؤ

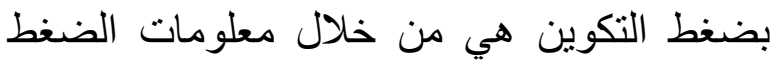

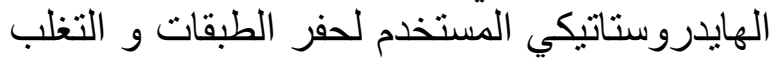

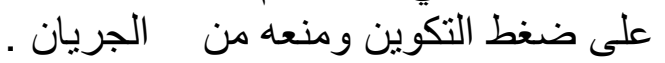

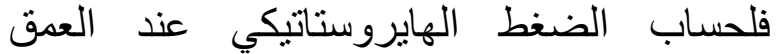
1139 متر أي عند قمة التكوين في البئر لحيس-6 فئي الذي حصل فيه جريان لماء التكوين بعد فقدان فين لئن كلي لدورة طين الحفر عند العمق 1139 مثر . الضغط الهايدروستاتيكي لعمود الطين على العمق لقن - 1139
Evaporates 3-1-1 المتبخر ات تتكـون صـخور الانهايـدر ايت مـن ترسـب كبريتـات الكالسـيوم

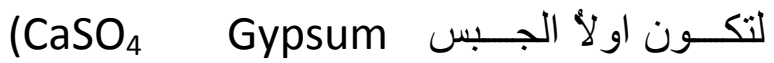

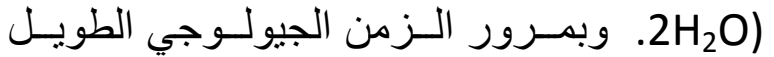
وبفعل العمليات الجيولوجيـة المتنوعـة مـن انحسـار

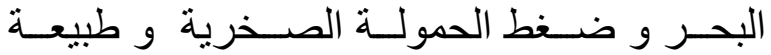

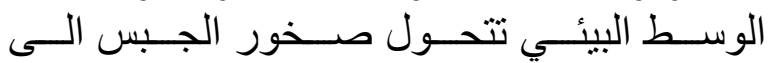
الانهايدر ايت Ca SO4 (شكل 8 ) ).

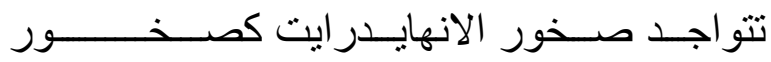

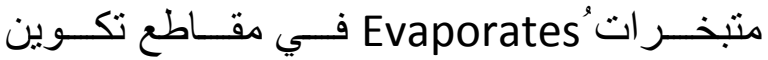
الطيار ات و بشكل طبقات يتر اوح سمكها ( 0.5 1.5 كما تتو اجد بشكل طبقات رقيقة streaks و بشكل

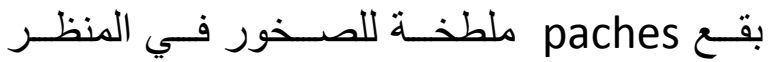

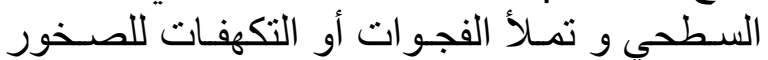

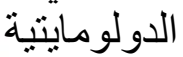

Water Flow 4-1-1

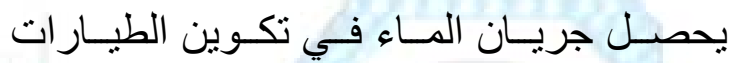

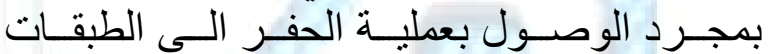

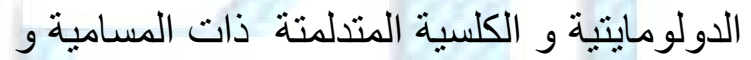

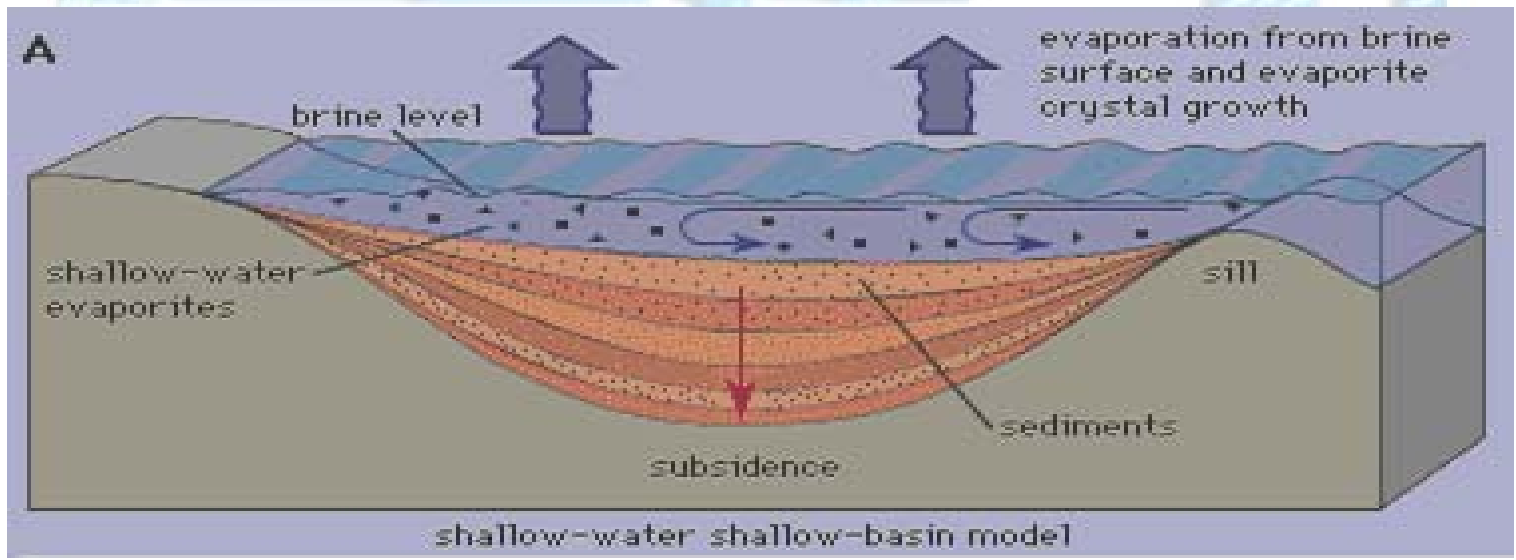

شكل (8) عملية تكون الانهايدر ايت(نقال" عن Encyclopedia Brittanica Inc,1998)

فلحساب الضغط الهايروستاتيكي عند العمق 1139 متر أي عند قمة التكوين في البئر لحيس-6 الذي حصل فيه

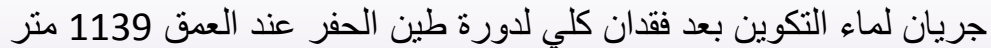

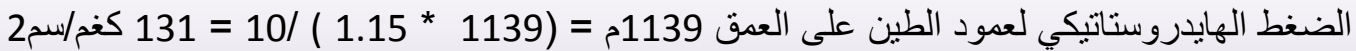

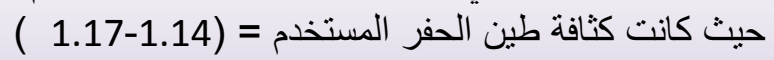

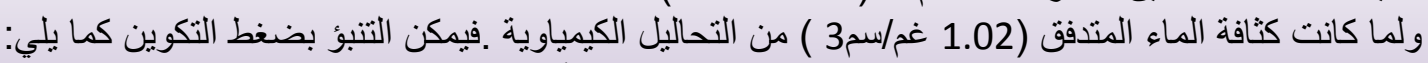

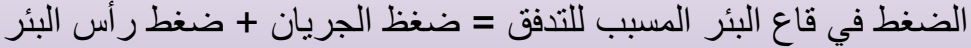

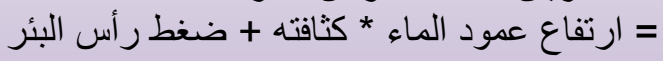


$1135-1122$

100

1112- 1109

100

جدول (2-1) اللباب المقطوع للبئر لحيس - 8

يظهر بان تكوين الطيار ات في حقل اللحيس يتكون من ثلاثة وحدات تحتوي على الماء الجوفي وهي كما يلي :

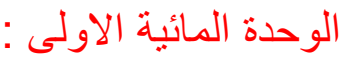

يؤخذ أعلى الوحدة على اساس وجود طبقة السئل السجيل

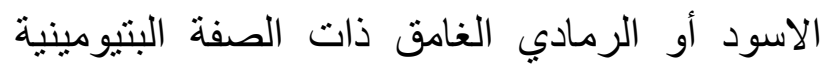
Bituminous Shale وبسمك لايتجاوز (0.5 م) تعمل هذه دانه الطبقة اضافة الى المقطع الدولومايتي الكثيف الواقع تحتها كحاجز قام بحبس المياه الجوفية في تكوين الطيارات . يتر اوح سمك هذه الوحدة من (60 م) في البئر لحيس -13 الواقع شمال الحقل ويقل بأتجاه جنوب الحقل ليصل الى الى الى (25 م) في البئرلحيس - 21 وتتكون من تعاقب الصخور

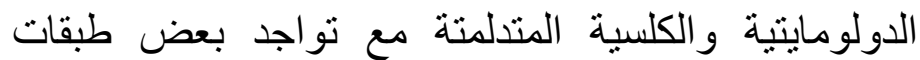
الانهيدرايت التي يتراوح سمكها من (0.2- 0.5 م) . تتصف هذه الوحدة بمسامية صوتية سالبة بسبب كثافة

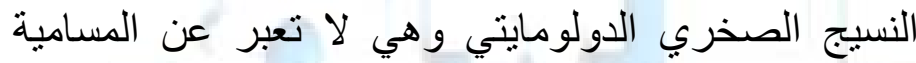

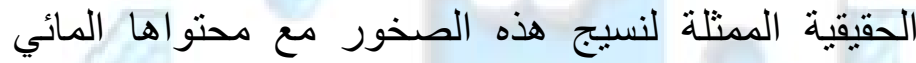
بسبب ان المجس الصوتي لا يتاثز بالمسامية الثانوية

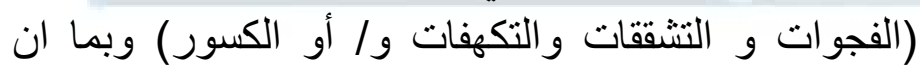
مجس الكثافة و النيوترون غير مسجل في مقاطع تكوين الطيارات عدا تسجيل واحد لمجس النيوترون في البئر لحيس -6 لذا من الصعب بمكان تحديد القيمة الكمية للمسامية لتلك الصخور الممثلة للوحدات المائية ولكل بئر ،أما في البئر لحيس-6 فأن المسامية الثانوية لصخور الوحدة المائية الاولى فبلغت بحدود (25-35) وحدة مسامية وتقل فئل قيمتها في الوحدة المائية الثانية حيث تسجل مسامية ثانوية بحدود (20-30 ) وحدة مسامية وتقل أكثر في الوحدة

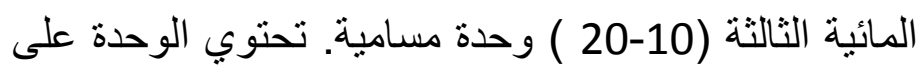
فترة عمقية (1130-1150 م) تسجل مقاومة كهربائية عالية مقابل انحراف جهذ ذاتي موجب لمقطع من الصخور

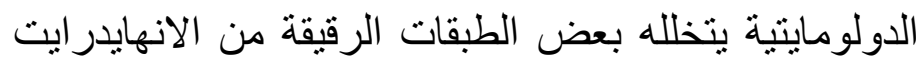

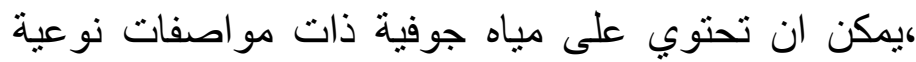

Oil Staining 5-1-1 التصبغات النفطية

لم يسجل الجيولوجيون العاملون على مواقع الحفر الذين اشرفوا على عمليات

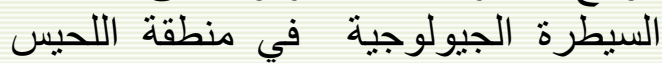
أي شواهد نفطية عن التصبغات النفطية

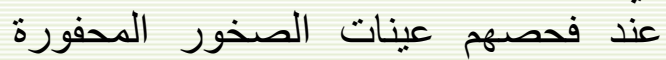

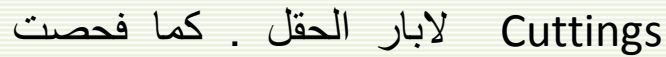
القترة العمقية (1135-1122) م في لار لباب

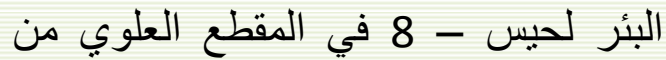

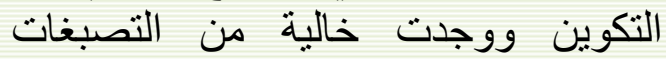
النفطية ، مع ان شو اهد و تصبينات نفطية سجلت لفترات عمقية من التكوين و و خاصة الفئة في جزئه الاسفل في حقول فئل الرمبلة الجنوبي و الثمالي و نهز عمر .ومما تجدر التهر الاشارة اليه بأن دولة الكويت تدرس حاليا"

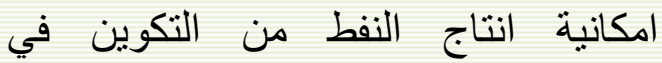
مساحات محددة من حقل البرقان بعد تقبيم

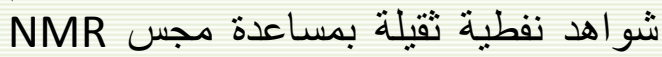
.(NUCLEAR MAGNETIC RESONANCE LOG) 2- التقبيم البتروفيزيائى

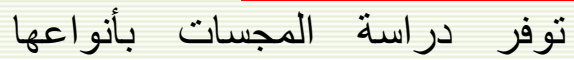

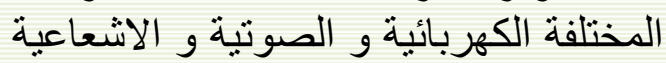

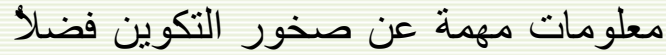

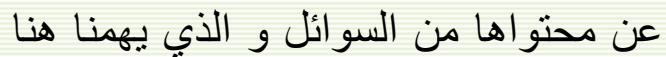

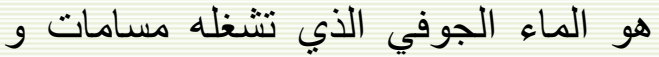

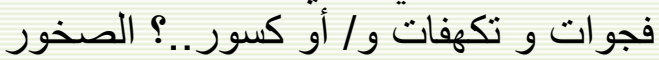
الدولومايتية و الصخور الكلسية المتدلمتية وصخور الانهايدر ايت لتكوين الطبار ات في الني حقل اللحيس. ومن خلال دراسة سجلات الجس الجس المنوفرة ومراجعة نقارير الفحص العيني لنماذج لباب البئرلحيس - 8 (جدول 2 (لفئل 2 )

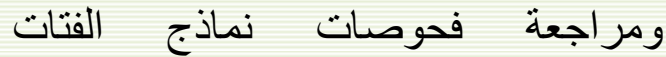

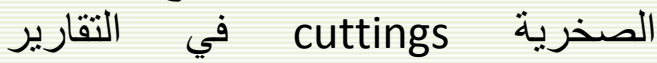
الجيولوجية لابار الحقل ومراجعة تقارير

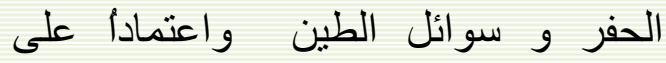
المجسات المتوفرة تم رسم مقطع طباقي

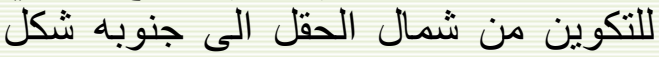

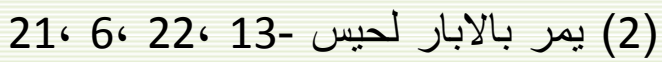


ان التقييم البتروفيزيائي اعلاه أعتمد على دراسة المجسات و المواصفات الليثولوجية لصخور التكوين أما نوعية الهين المياه الجوفية والتي سيتم التطرق اليها في الفقرة القادمة والتي التي التي التيات

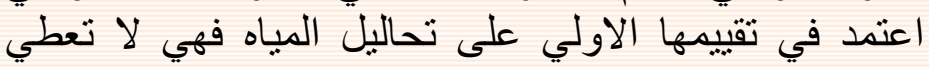

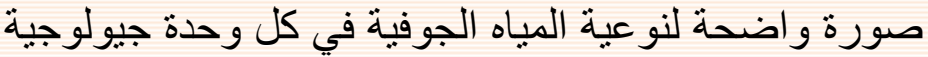
من الوحدات المائية الثلاثة للتكوين ـ و ومن خبرتنا العملية في

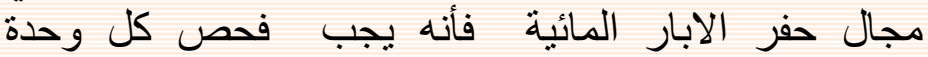
جيولوجية بشكل منفرد بواسطة عمليات الفحص الطبقي

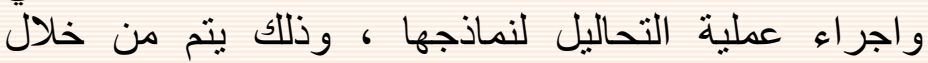
السيطرة الجيولوجية على حفر البئر واجراء عملية الفحص

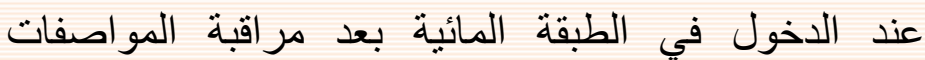

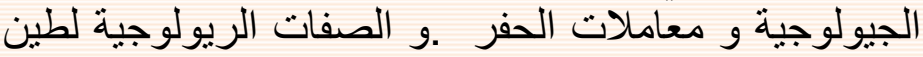
الحفر و اعطاء التوصيات بأختيار الفترة العمقية المؤهلة لعملية الفحص الطبقي .

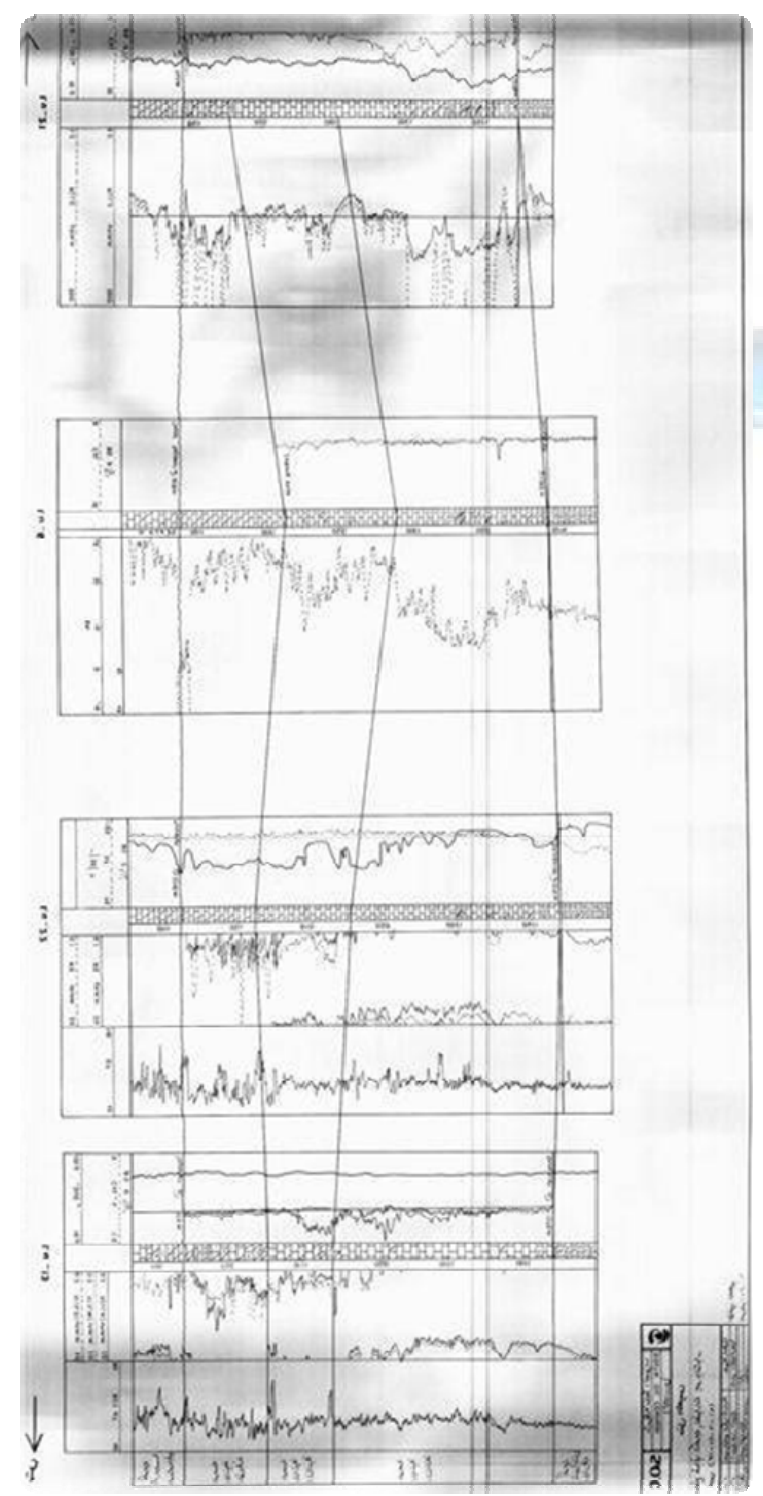

شُكل رقم (9) مقطع طباقي لتكوين الطيارات يمر بالابار

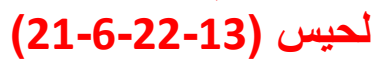

ـ الوحدة المائية الثانية: يتراوح سمك هذه الوحدة من (45)

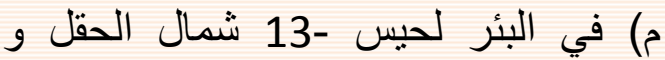
تزداد بأتجاه جنوب الحقل حتى تصل الى فئى

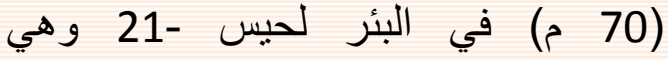
محصورة بين طبقتين كلسيتين ذات محتوى

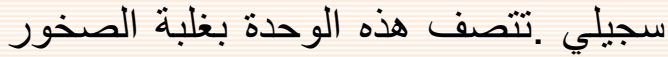

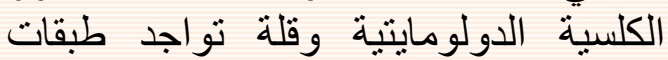

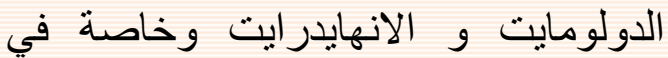

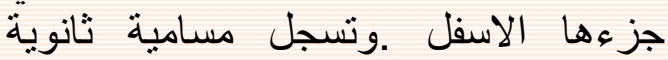
بحدود (20- 30) وحدة مسامية في البئر لحيس - 6 ومن تسجيلات مجس قياس قطر

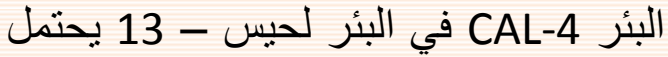
أن تحتوي هذه الوحدة على كسور في في جزءها الاسفل ويمكن أن تكون هي النه السبب

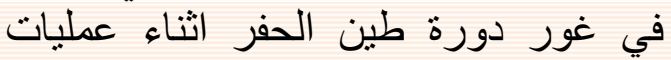
حفر الابار. و ولا يعطي مجس الجهد الذاتي

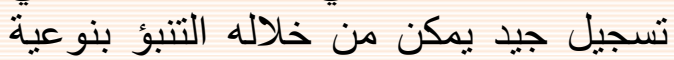
المباه التي تحتويها هذه الوحدة.

الوحدة المائية الثالثة : - الثان وهي اكبر الوحدات المائية في التكوين كيتراوح سمكها من (150 م) في البئر لحيس - 13 شمال الحقل و يتناقص باتجاه جنوب الحقل ليصل الى (120 م) في البئر لحيس - 21 ـ تتصف الوحدة بمقطع من الصخور الكلسية ذات محتوى سجيلي عال في جزءها الأعلى ويحتمل ان تتواجد

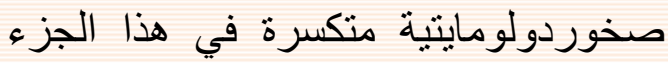

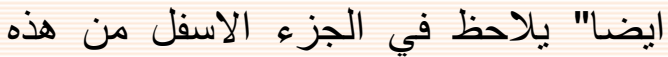

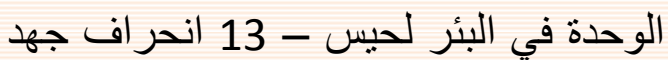
ذاتي موجب مقابل طبقات كلسية دولو مايتية

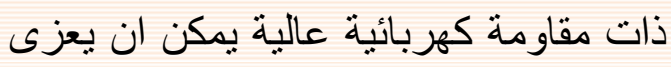

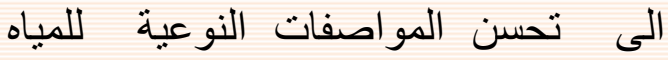
الجوفية في هذا الجزء من الوحدة الصخرية

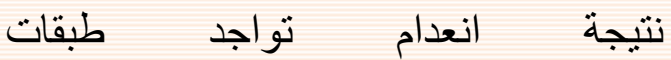
الانهايدرايت.بلغت المسامية الثانوية في في في البئر لحيس - 6 بحدود (10- 20) وحدة مسامبة. 
النقي قيمـة الأس الكيـدروجيني لهــا

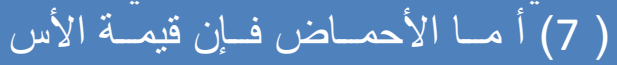

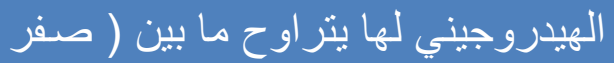

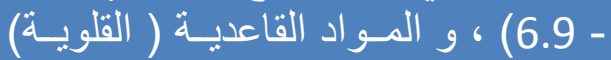

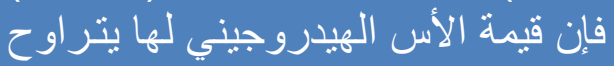

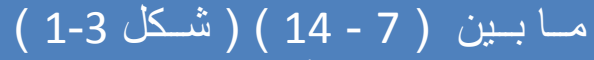

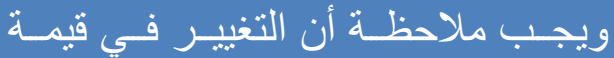

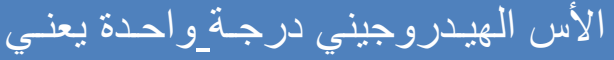

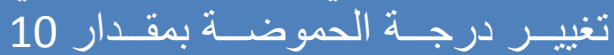

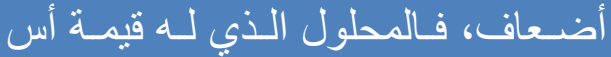

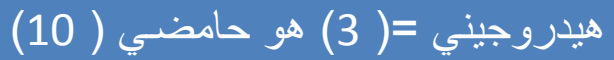

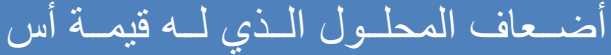

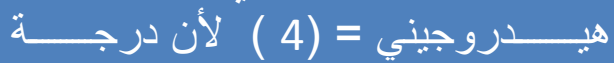

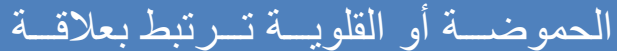

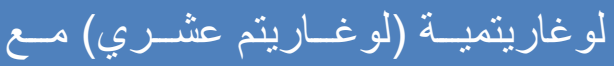

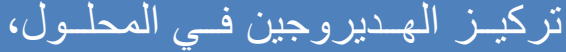

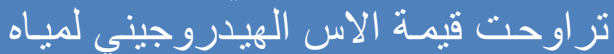

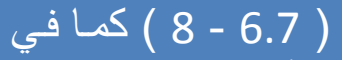

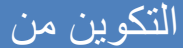
جدول (3-1 ) وهي أفرب الى المحلول

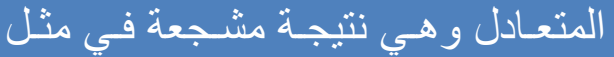

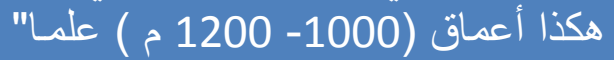

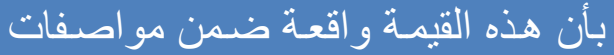

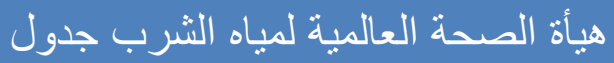

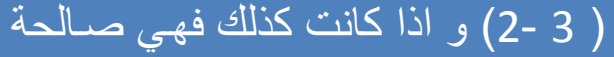
لجميع الاستخدامات بقدر ما تتعلق بهذه

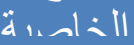

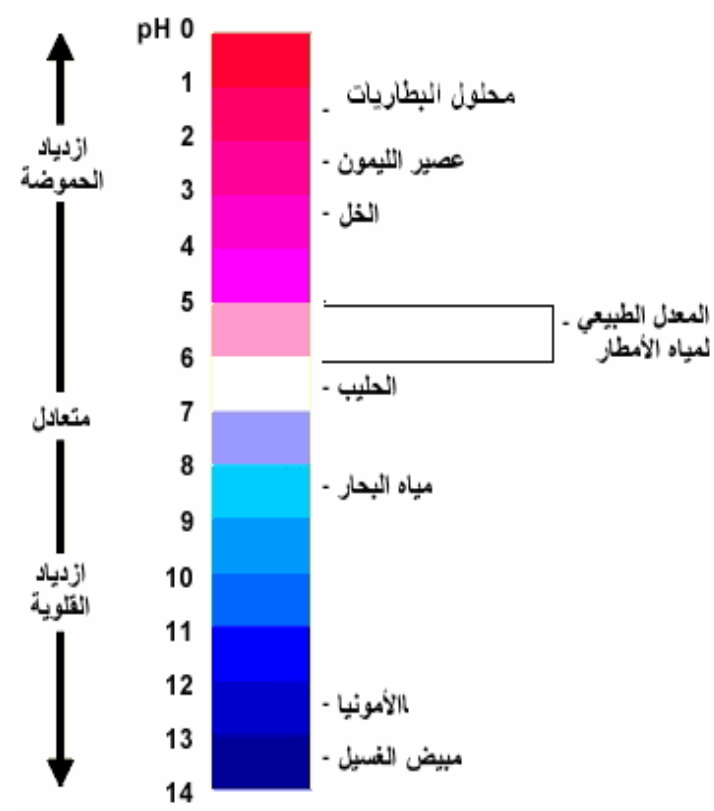

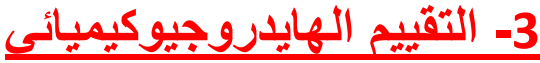

هنالك عدة تحاليل يمكن بو اسطتها تقييم نوعية المياه

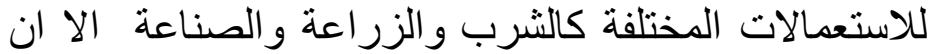

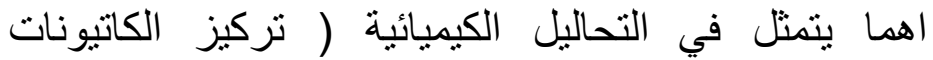
والانيونات) اي معرفة محتوى المياه من الاملاح الذائبة

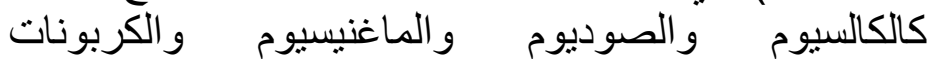
و البيكربونات و الكلور ايد و الفلور ايد و النتر ات، و وهناك نوع والفرئ

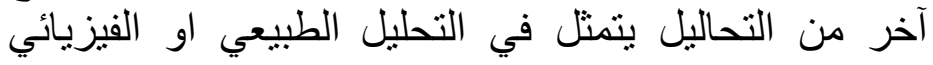

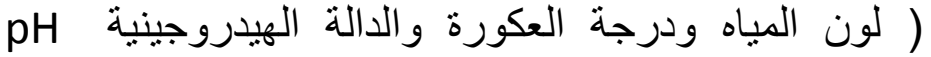

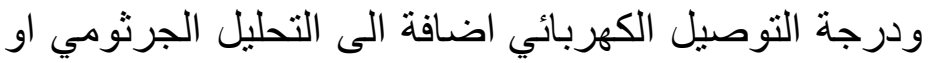

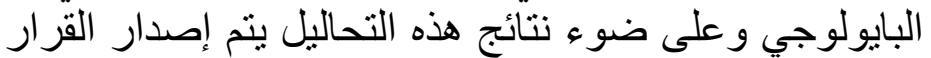

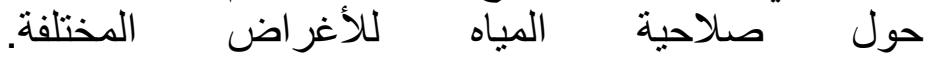
أجريت محاولة أولية لتقييم نوعية المياه الجوفية لتكوين

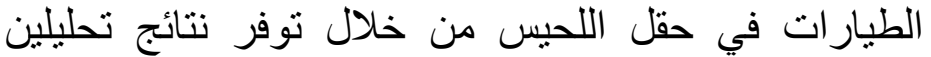
كيميائيين لمياه التكوين للبئرين لحيس-4 و لحيس-6 وهما بئران نفطيان تم حفر هما عامي 1974 و 1975 لغرياه 1974 انتاج النفط من مكمني نهر عمر و الزبير كما تم التحرك

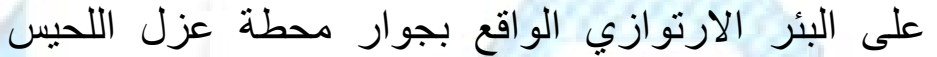

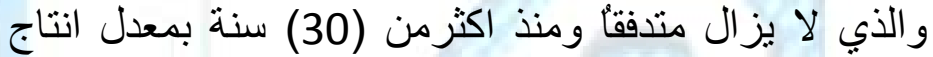

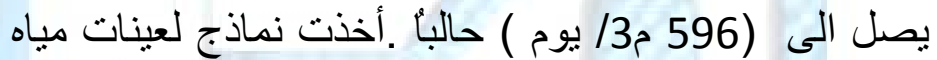

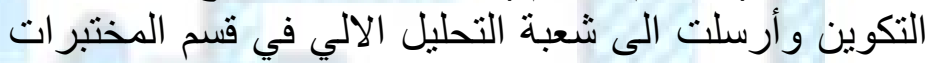

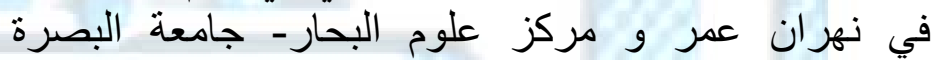
أجريت بعض التحاليل التقليدية لبعض المو اصفات الفيزيائية.

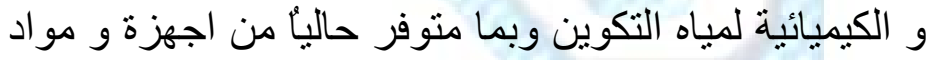
كيميائية لدى الجهتين ومن خبرتنا العملية في مجاه ونال حفر

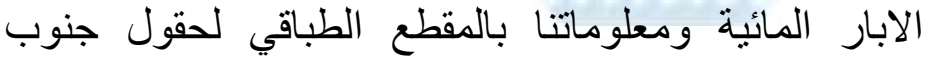

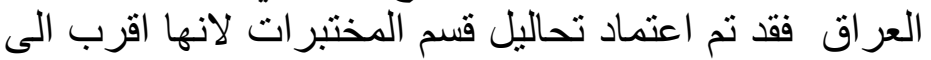
حقيقة مواصفات التكوين ومياهه الجوفية أما ل التحليل الجرثومي و البايولوجي فقد أجري من قبل قسم البيئة في دائرة كهرباء النجييية.

\section{1-3 المو اصفات الفيزيائية} PH 1-1-3 الاس الهيدروجيني

أن زيادة تركيز أيون الهيدروجين تعني زيادة الحموضئة لهذا

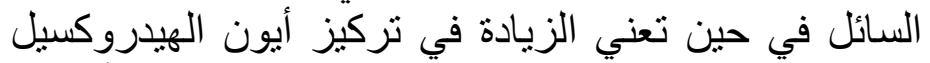

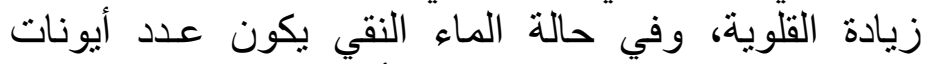

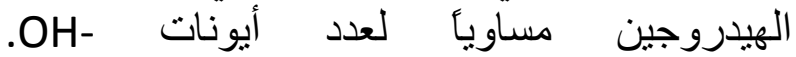

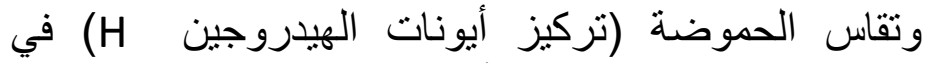

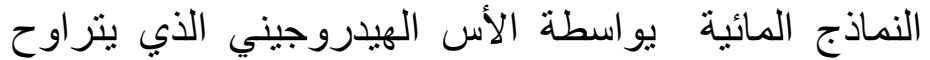
بين ( صفر - 14) فالمحاليل المتعادلة الحموضة الائة مثل الماء لئي 
جدول (2) مقارنة هايدروجيوكيميائية للمياه الجوفية لتكوين الطيار ات ـ حقل اللحيس

\begin{tabular}{|c|c|c|c|c|c|c|c|c|c|c|c|c|c|c|}
\hline Well & $\begin{array}{l}\text { Top } \\
\text { (m) }\end{array}$ & $\begin{array}{r}\text { Thick. } \\
\text { (m) }\end{array}$ & $\underset{\mathrm{mg} / \mathrm{l}}{\mathrm{Na}^{+}}$ & $\underset{\mathrm{mg} / \mathrm{Ca}}{\mathrm{Ca}^{++}}$ & $\underset{\mathrm{mg} / \mathrm{l}}{\mathbf{M g}_{\mathbf{g}}^{++}}$ & $\mathbf{K}^{+}$ & $\underset{\mathrm{mg} / \mathrm{l}}{\mathrm{Cl}^{-}}$ & $\underset{\mathrm{mg} / \mathrm{l}}{\mathrm{CO3}^{--}}$ & $\underset{\mathrm{mg} / 1}{\mathrm{HCO3}^{-}}$ & $\mathrm{SO}_{\mathrm{mg} / \mathrm{l}}^{--}$ & PH & $\begin{array}{c}\text { Sp.Gr. } \\
\mathbf{g} / \mathbf{c m}^{3}\end{array}$ & $\underset{\mathbf{m g} / 1}{\text { TDS }}$ & $\underset{\mathbf{m g} / 1}{\mathrm{H} 2 \mathrm{~S}}$ \\
\hline Lu -* & ? & ? & $x$ & 728 & 345 & $x$ & 1022 & Nil & 269 & 2653 & 7.65 & 1.0067 & 6000 & 51 \\
\hline Lu -4 & 1151 & 242 & 1160 & 640 & 220 & $x$ & 1310 & & 230 & 2650 & 6.7 & 1.0063 & 6540 & $x$ \\
\hline Lu -6 & 1139 & 253 & 1020 & 810 & 290 & $x$ & 1460 & & 300 & 2980 & 8 & & & $x$ \\
\hline
\end{tabular}

العلامات : 1 - * البئر الارتوازي لمحطة عزل اللحيس 2- ? لا توجد معلومات 3 - × لا توجد تحاليل

جدول (3)المو اصفات العالمية لمياه الثرب (المصدر www.myah.net )

\begin{tabular}{|c|c|c|c|c|c|}
\hline الروسية & الأمريكية & المواصفيةت & الالاوروبية & هويئة الصحة & العنصر أو المادة \\
\hline- & 15 & 15 & 20 & 15 & TCU اللون \\
\hline- & 500 & 500 & - & 1000 & المواد الصلبة الذائبة \\
\hline- & - & - & - & - & المو اد الصلبة المعلقة \\
\hline- & $1-5$ & 5 & 4 & 5 & NTU العكارة \\
\hline- & $8.5-6.5$ & $8.5-6.5$ & $8.5-6.5$ & $8.5-6.5$ & الاس الهيدروجينى PH \\
\hline 4 & - & - & - & - & الأكجسين المذاب \\
\hline- & - & - & - & 500 & $2 \times 1 \times x \times 1$ \\
\hline 2 & - & - & - & - & نيتروجين نشادرى (امونيا ) \\
\hline 2 & - & - & 0.5 & - & الأمونيوم \\
\hline- & 10 & 10 & - & 10 & نترات معين بالنيتروجين \\
\hline 10 & - & - & 50 & - & النترات \\
\hline 1 & - & 1 & - & - & نتريت معين بالنيتروجين \\
\hline 1 & - & - & 0.1 & - & النتريت \\
\hline- & - & - & 5 & - & الفوسفور P \\
\hline 2 & - & - & - & - & حدود الاكسجين الحيوي BOD \\
\hline- & - & - & $175-150$ & 200 & الصوديوم Na \\
\hline 250 & 250 & 250 & 25 & 250 & CI الكوريد CI \\
\hline 500 & 250 & 500 & 25 & 400 & So \\
\hline- & - & 0.05 & - & - & كبريتيد \\
\hline 1.5 & 2 & 1.5 & ${ }^{5}(0.7)-1.5$ & 1.5 & فلوريد \\
\hline- & - & 5 & 1 & - & بورون \\
\hline 0.1 & - & 0.2 & - & 0.1 & سيانيد \\
\hline- & - & - & 0.2 & 0.2 & الومنيوم \\
\hline- & 0.05 & 0.05 & 0.05 & 0.05 & ارسنك \\
\hline- & 1 & 1 & 0.1 & - & باريوم \\
\hline 0.001 & 0.01 & 0.005 & 0.005 & 0.005 & كادميوم \\
\hline $8(0.5) 0.1$ & 0.05 & 0.05 & 0.005 & 0.05 & كروميوم كr \\
\hline 0.1 & - & - & - & - & كوبلت \\
\hline 1 & 1 & 1 & $1(0.1)$ & 1 & نحاس \\
\hline 0.5 & 0.3 & 0.3 & 0.3 & 0.3 & حديد \\
\hline 0.03 & 0.05 & 0.05 & 0.05 & 0.05 & رصاص Pb \\
\hline
\end{tabular}




\begin{tabular}{|c|c|c|c|c|c|c|c|}
\hline - & 0.05 & 0.05 & 0.05 & 0.1 & & $\mathrm{Mn}$ & منجنيز \\
\hline 0.0005 & 0.002 & 0.001 & 0.001 & 0.001 & & $\mathrm{Hg}$ & زئبق \\
\hline- & - & - & 0.05 & $\begin{array}{ll}- & \text { r }\end{array}$ & & $\mathrm{Ni}$ & نيكل \\
\hline - & 0.01 & 0.01 & 0.01 & 0.01 & & $\mathrm{Se}$ & سلينيوم \\
\hline 1 & 5 & 5 & (3) -0.1 & 5 & $\mathrm{Zn}$ & زنك & \\
\hline
\end{tabular}

جدول (3- ب ) المو اصفات العالمية لمياه الثرب (المصدر Www.myah.net )

\begin{tabular}{|c|c|c|c|c|c|}
\hline الروسية الموفات & الامريكية المفات & الكندية اصفات & الالموروبية & الصو اصفةات & الملوثات العضوية \\
\hline 0.3 & - & - & 0.01 & - & $\begin{array}{rr}\text { Oil \& } \begin{array}{r}\text { Petroleum } \\
\text { Products }\end{array} \\
\end{array}$ \\
\hline - & - & 0.1 & 0.5 & - & Total Pesticides \\
\hline- & - & - & 0.1 & - & $\begin{array}{c}\text { Individual } \\
\text { Pesticides }\end{array}$ \\
\hline- & - & 0.7 & - & 0.03 & Aldrin \& Dieldrin \\
\hline - & - & 30 & - & 1 & DDT \\
\hline- & 0.4 & 4 & - & 3 & Lindane \\
\hline- & 100 & 100 & - & 30 & Methoxychlor \\
\hline- & 5 & - & - & 10 & Benzene \\
\hline- & - & - & - & 0.01 & Hexachlorobenzene \\
\hline - & - & 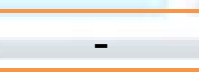 & - & 10 & Pentachlorophenol \\
\hline 1 & - & 2 & 0.5 & - & Phenols \\
\hline 0.5 & $12(0.5)$ & - & 0.2 & - & Detergents \\
\hline
\end{tabular}

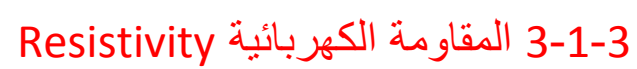

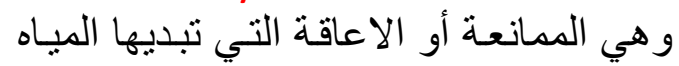

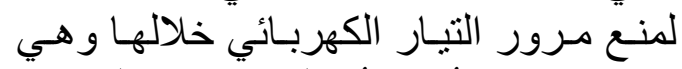

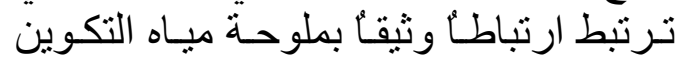

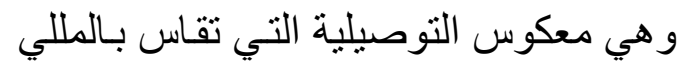

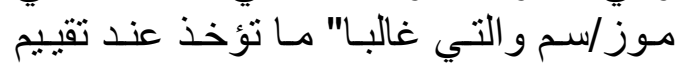
مو اصـفات المبـاه التي تعتبـر كدالـة لتركيز

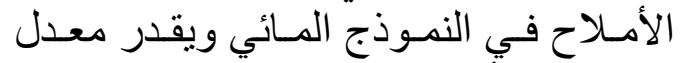

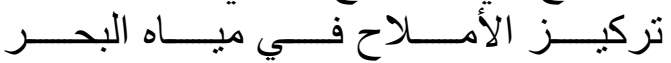

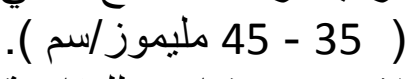

لا يوجد قياس للمقاومة الكهربائية في التحاليل الكيمياوية المتوفرة ولأستخر اجها من مخططات شلمبرجر وبشكل غير دقيق الخد طبعاً بعد أخذ قيمة الملوحة فئل المستخرجة من المجسات والتي تساوي (5000 جزء بالميون) عند العمق 1431 م
Specific Gravity 2-1-3 الوزن النوعي

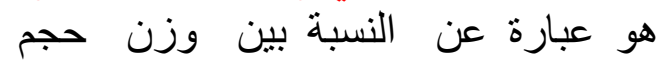

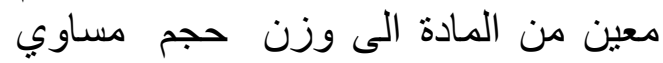
لبعض المواد الاخرى المستعملة كمقياس ويقترب الوزن النوعي للمياه الجوفية الإنية لتكوين الطيار ات من الوزن النوني النوعي للمياه

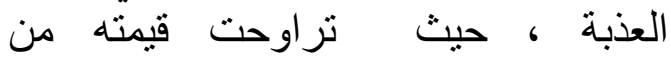

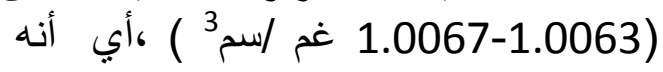
يبتعد كثيرا" عن كثافة الماء المالح الذي يبلغ وزنه النوعي( 1.026 غم /سم33). فبرغم حرارة التكوين في منثل هكذا أعماق ورغم النظام المائي المغلق تقريبا" لوفي لوقوع صخور التكوين الحاملة للماء في خزاني فئات جوفية محصورة نرى بأن قيمته تقترب من قيمة الوزن النوعي للمياه العذبة. 
( 0.9 اوم-متر ) وهذه القيمة عالية جدا"

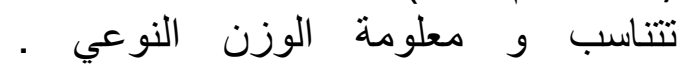

- 9000 جزء بالمليون ) في حقل غرب القرنة ويزداد في حقل اللحيس ليصل في اللى (16000 جزء بالمليون). بلغ تركيز ايون الكالسيوم في مياه

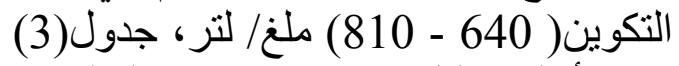
وهي أعلى بقليل من قيمة تركيز الكالسيوم

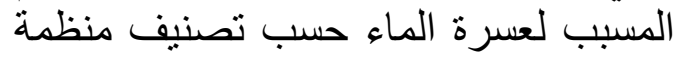
هيأة الصحة العالمية حيث يجب العبد أن لا يزيد

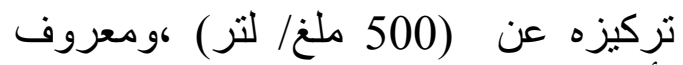
بأن هنآك نوعين من عسرة الماءوالعسرة العرة الدائمية وهي المياه المحتوية علي كمين كيات العيات العيرة من كبريتات وكلوريد كل من الكياه الكالسيوم و الماغنسيوم ، أما العسرة المؤقتة فهي التي لئي تحتوي على البيكاربونات الناتجة من ذَوبان النيان

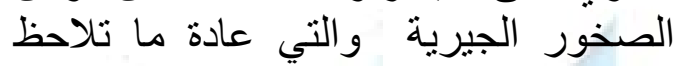
بشكل ترسبات كلسية داخل الانابيب الني

المياه اليسرة هى تلاك المباه المحتوية تحويها. علي كميات قلبلة من ايونات الكالسيوم الكياه

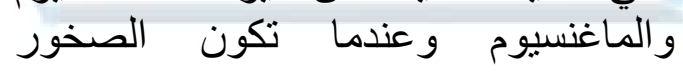

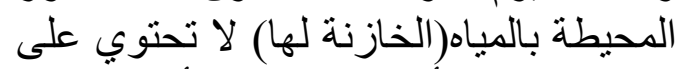

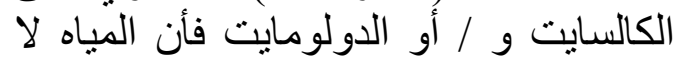

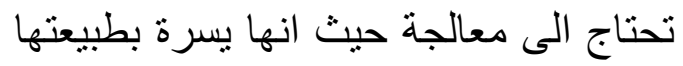

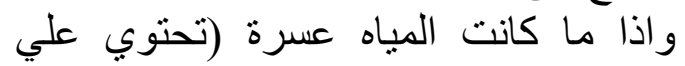
نسب من الكالسيوم و الماغنسيوم وتر الكير الكيز قليلة من الباريوم والسترونشيوم) فلابد من

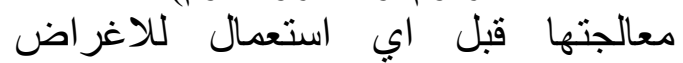

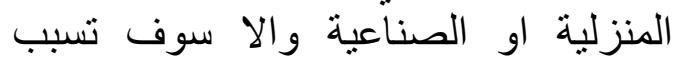
انسدادا للأنابيب و الأجهزة المستخدمة.

3-2-3 المغنيسيوم

ان مصدر ايون المغنيسيوم في ميـاه

التكوينات الجيولوجية هو الصخور الكلسية الصية

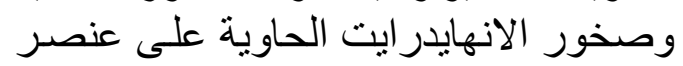

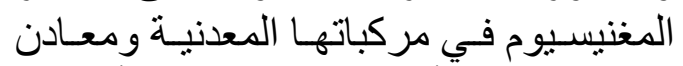

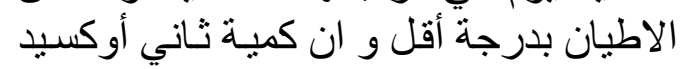
الكاربون الـذاب في المـاء هي التي تحدد التهد

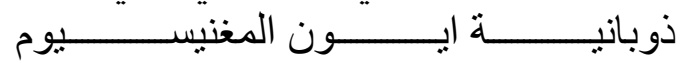

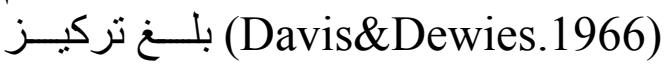

من تكوين الثيرانش (أسفل الطبارات) في

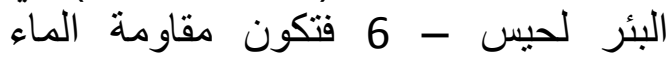
الجوفي في تكوين الطيارات تساوي -0.8

2-3 المواصفات الكيميائية 1-2-3 الصوديوم اصني

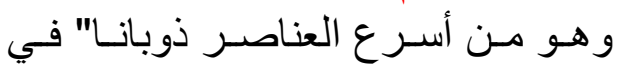

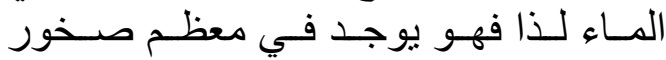

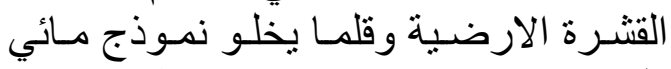

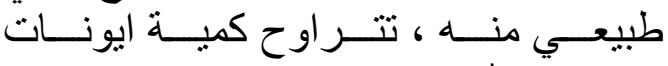

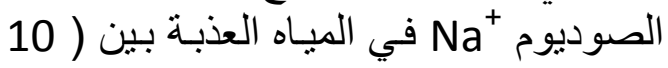

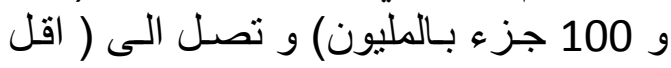

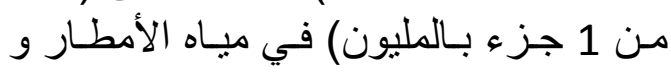

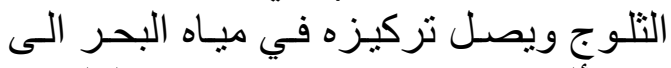

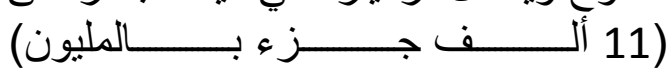
(Livinstone.1973) ويصل الى اكثر من (140)

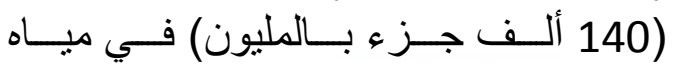

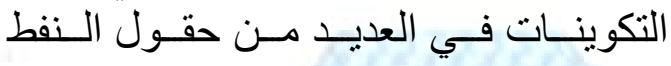

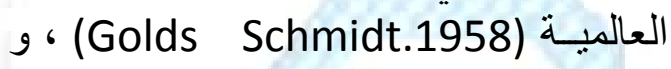
يصل تركيزه في مياه تكوين اليمامـة في في

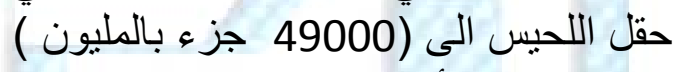

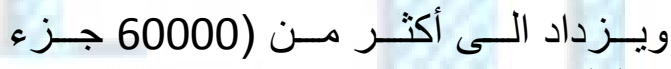

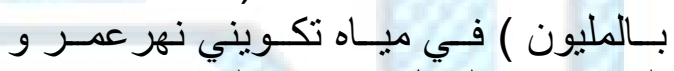

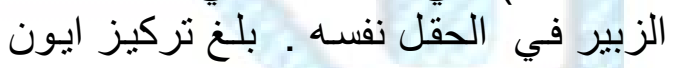

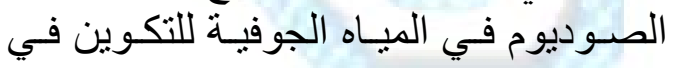

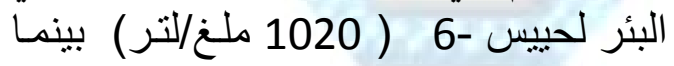
كان اعلى في اليئر لحيس-4 حيث وصلئ لئل تركيزه الى (1160 ملغ فئلتر).

2-2-3 الكالسيوم

تعتبر عملية التجوية للصخور

الكلسية (Calcite \& Dolomite)

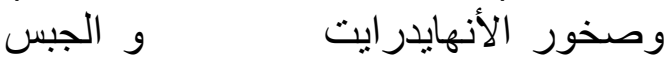
Anhydrite \& Gypsum المسؤول عن زيادة تركيز الكاسيوم و العئيوي

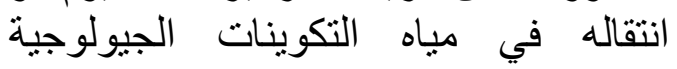

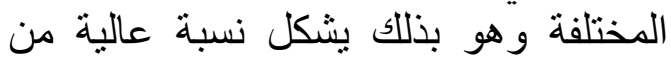

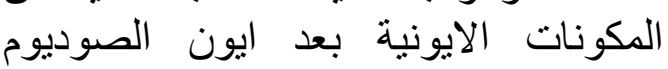
فيصل تركيزه في مياه البحر الى ( 200 -

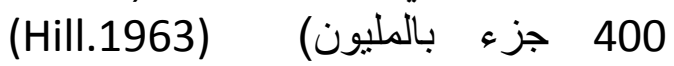

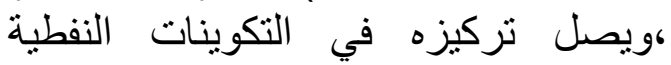
الكلسية (المشرف و اليمامة ) الى ( 8000 
المغنيسيوم في مياه البحر بصل الى (1300)

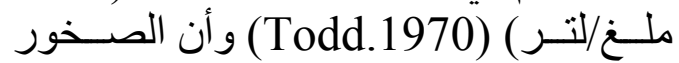

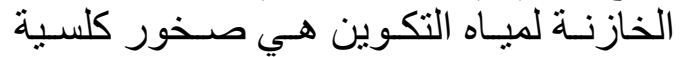

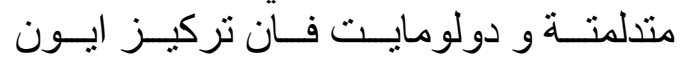

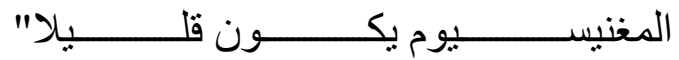

أقله في البئر الارنوازي القريب من محطة

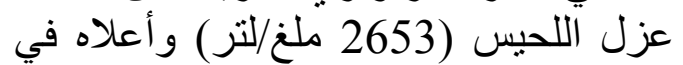

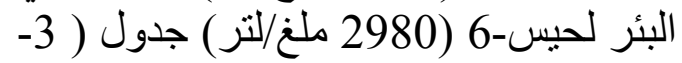
1 ) ، ،ان التركيز العالي للكبريتات في المياه الجوفية يمكن أن يعزى الى أن أن الصل هذئ النياه

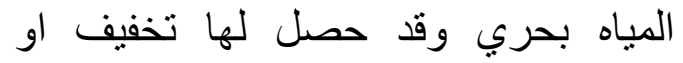
اضيف لها ماء مترشح غني بالكبريتات (Alhassar.1975) العالي لايون الكبريتات في مياه التكوين حالة طبيعية لمباه جوفية محصورة و و واقعة ولئة ضمن مقطع رسوبي تتعاقب فيه صنيه صنور الانهايدرايت مع الصخور الكلسية الهندلينة

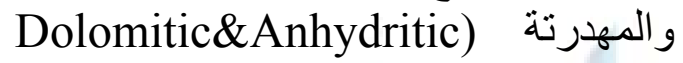
Limestone (Rocks للكبريتات هو نتيجة غير مشجعة وتحتاج

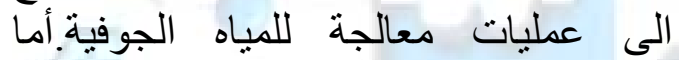
التركيز العالي للكبريتيدات فسوف لتئي يتم مناقشته في فقرة كبريتيد الهيدروجين.

$$
\text { 6-2-3 الكربونات و البيكاربونات }
$$

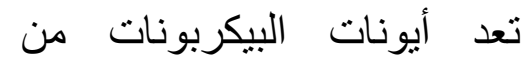

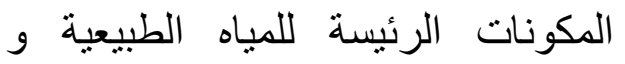
تتكون من تفاعل كل من ثاني اوكسيد للكيداه

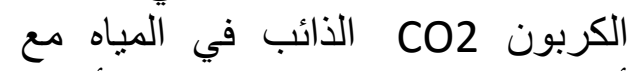
أنواع الصخور الجيرية المكونة أساسا من كربونات الكالسيوم 3 3 ويصبح لدينا القاعدة التالية المسببة للعسر المؤقت للماء الذي يزاء لمال عادة بواسطة غليان الماء ثم ترويقه في الأي أحواض خاصة.

\section{$2 \mathrm{CaCO}_{3}+\mathrm{H}_{2} \mathrm{O}+\mathrm{CO}_{2} \rightarrow 2 \mathrm{CaHCO}_{3}$}

و تتراوح نسبة البيكربونات في المياه الجوفية بين 50 و 400 جزء الميكرئ بالمليون،

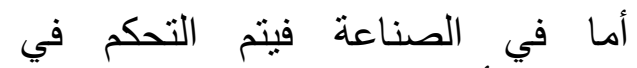

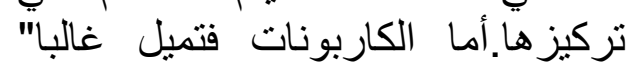
الى تكوين أملاح و مركبات غير ذائبة
أيون المغنيسيوم في مياه التكوين في البئر

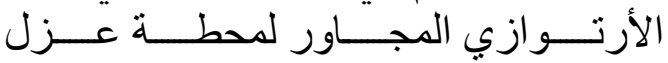

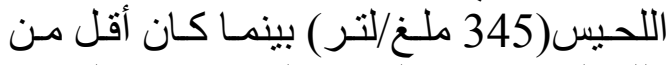

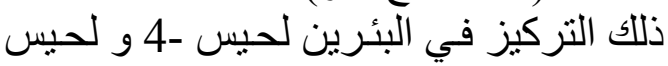

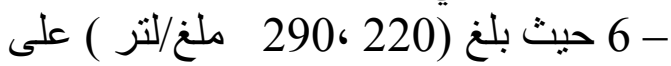

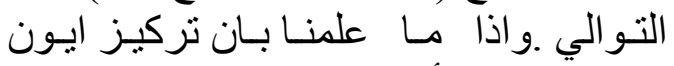

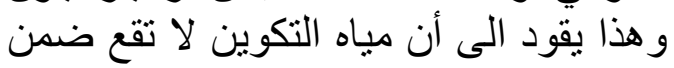

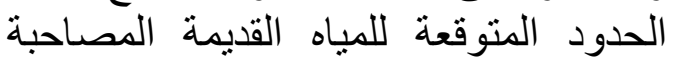
للنفوطو انما من مياه مختلطة بمياه سطحية. 4-2-3 الكلور ايد ويتو اجد في المياه عادة بشكل كلوريد

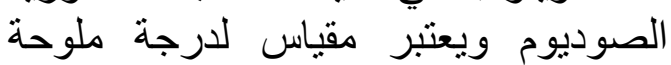
المياه ، ويتفاوت تركيزه من القيليل (مياه

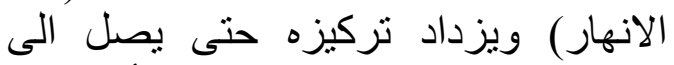
درجة الاشباع او فوق الاشباع (أكثر من الثن

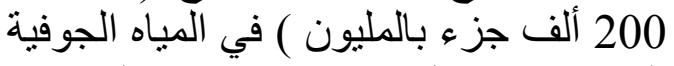
العميقة ، ويصل نركيزه في مياه البحار و والمياه المحيطات الى (19 ألف جزه في بـ بالمليون ) بينما يسجل أقل تركيز لله في مياه الامطار

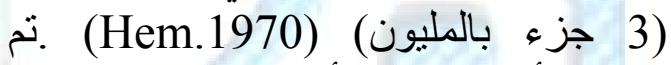
تسجيل أقل تركيز لأيون الكلور في مياه تكوين الطيارات في البئر الارنتوازي لائي

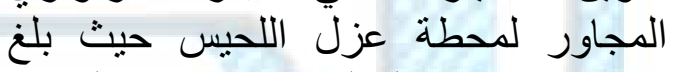
تركيزه (1022 ملغ/لتر) ويزداد في البئرين لحيس-4 و لحيس-6 لعيس (1310 و 1460 ملغ/لتر ) على التو الي.

\section{5-2-3 5 الكبريتات}

يعتبرذوبان وتجوية صخور الانهايدر ايت

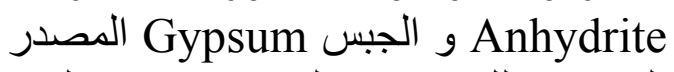

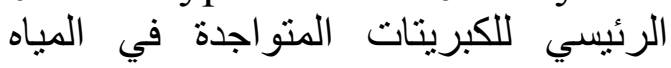

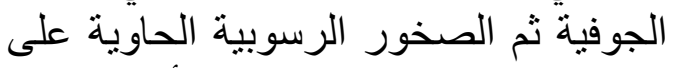
معدن الباير ايت pyrite بدرجة أقل ،كما قد المد

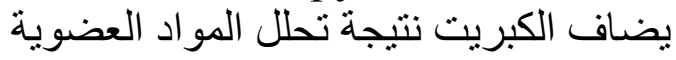

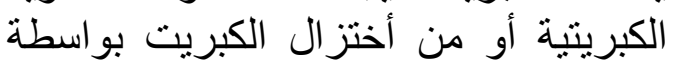

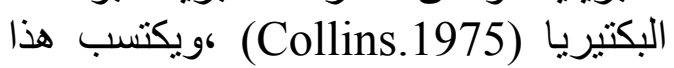
الايون أهمية في دراسة المياه الجوفية و في الهي الدراسات المكنية ، حيث الاتئ يميل هذا الايون

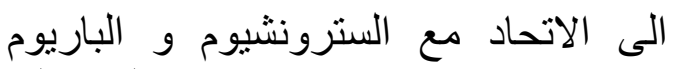

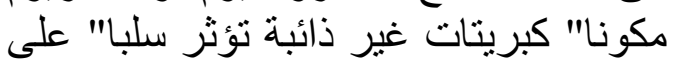

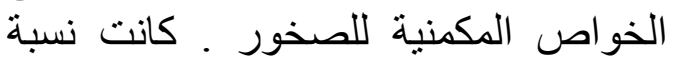
تركيز الكبريتات في مياه التكوين عالية وبلغ 
بلغ أعلى تركيز لأيون البيكاربونات في الحي

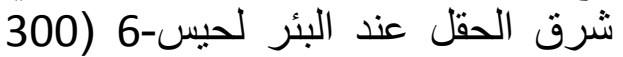
ملغ/لتز ) ويقل بأتجاه غرب الحقل لئر ليصل الى (230 ملغ/لتر) في البئر لحيس-4 ـ ل

الهواء حيث تصل كثافته النوعية الى رورئ (1.192 ) ودرجة حرارة اشتعاله (260)

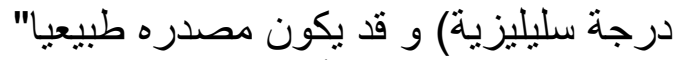

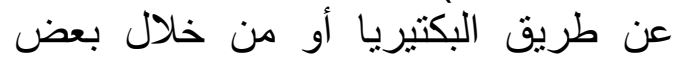

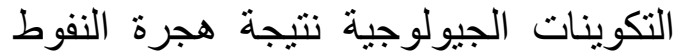
وتكونها أو في مناطق ترسبات الفحم في لاني

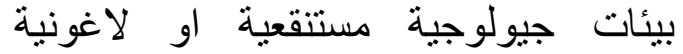

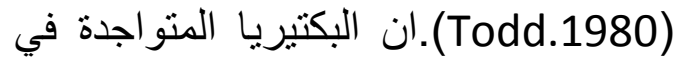

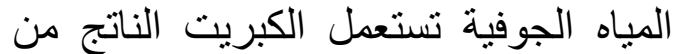

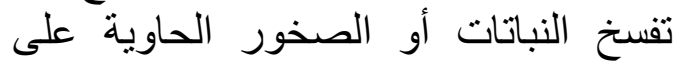
معادن الكبريت في بيئات مستنقعية اختز الية ينعدم فيها الاوكسجين تقريبا". و ويمكن التئن تحس الغاز من خلال رائحته الكريهة عندما يصل الى مستوى تركيز ( 5 ج.م.م.م) حيث يعطي صفة المياه المتعفنة للمياه

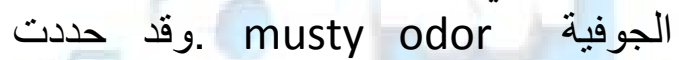
المعايير الدولية لغاز كبريتيد الهيدروجين

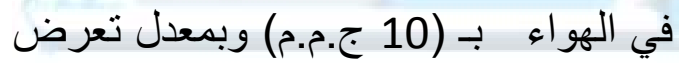

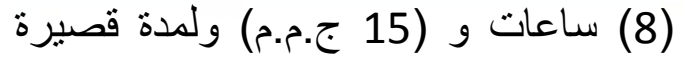

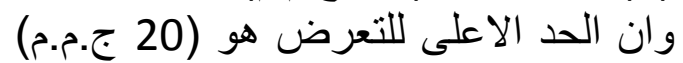

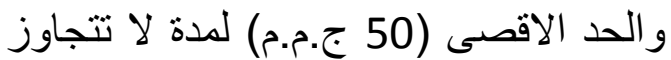

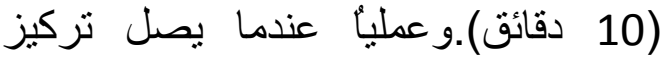
الغاز في الهواء الى (600 ج.م.م)يصبح قاتلا

وبما ان غاز كبريتيد الهيدروجين ذائب في المياه الجوفية فأن عملية النمذجة التية السطحية بواسطة الجريان الارنوازية لانية لانية لانية تعطي قيمة دقيقة لنسبة تركيز الغاز في في الإني المياه الجوفية الا اذا كان التحليل موقعيًا

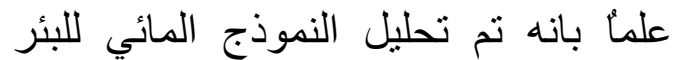

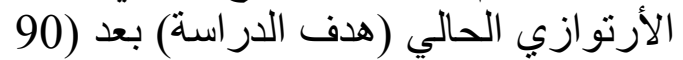

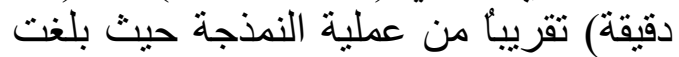
نسبة تركيزه في مياه التكوين بحدود (51) لزئة ملغ /لتر ) و هي نسبة عالية قابلة للزيادة لأن

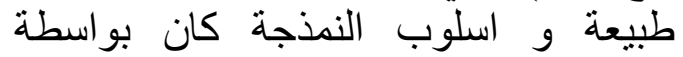
الجريان الأرتوازي من احد أفرع شجرة راس البئر المتضررة .
في الماء تؤثر سلبا" على حركة الموائع

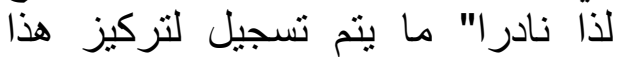
الايون في النماذج المائية.

T.D.S 7-2-3 الأملاح الكلية المذابة تحدد نوعية المياه بكمية المواد الدية التية التية

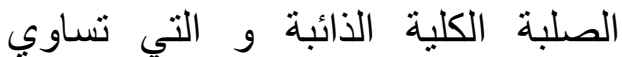

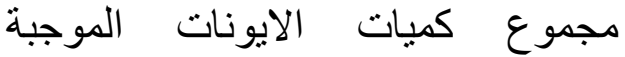

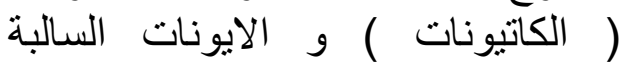

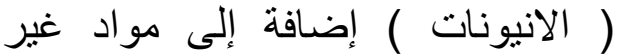
متأينة أخرى كالغاز ات المذابة في الماء. و قد حددت النسبة الصالحة للياه الثرب بأن تكون أقل من 500 جزء الماء لياه بالمليون و يسمح في حالات خاصنة بأن ألمان

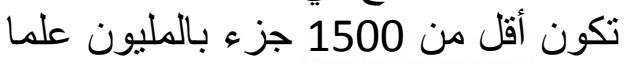
أن الزيادة عن هذا المعدل تؤدي إلى بلى وتختلـف كميــة و نوعيـة الأمـلاح

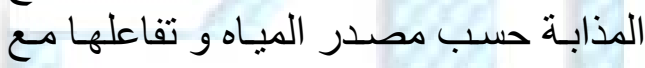
صخور التكوين والمسار الذي تسلكه من النس

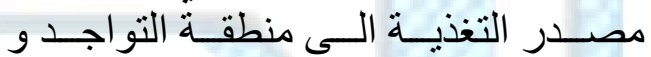

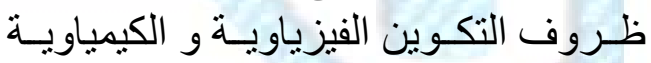

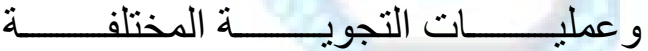

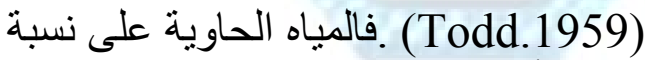
تركيز أملاح كلية قلبلة تعتبر مياه سطحية الحية

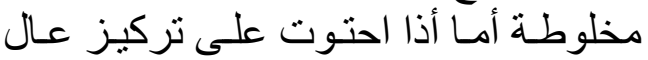

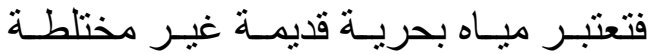

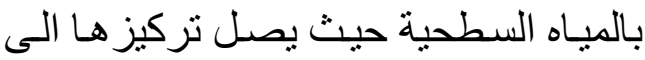

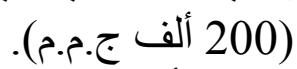
بلغ أعلى تركيز لكمية الاملاح الكلية

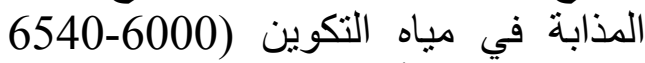
ج.م.م) علما بأن تركيز الاملاح الكلية الأبية الذائبة في بعض ابار المياه الجوفية لتكوين الإنيان

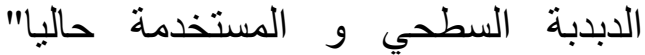

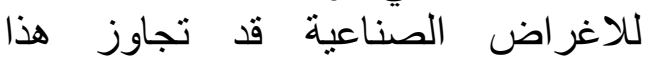

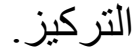

-2-3- 8 كبريتيد الهيدروجين كبريتيد الهيدروجين غاز عالئروجيم اللون وذو رائحة نفاذة ، وهو أنقل بقليل من 
التوصيات

1- نوصي بضرورة توفير معدات الفحص الطبقي للتجويف المفتو ح ليتسنى امكانبـة تقيبم التكوينات الجيولوجية الحاملة للماء الجوفي . 2- نوصي بالاستمرار في التعاون مع وزارة التهارة العلوم و التكنولوجيا - دائرة معالجة المياه لتقييم نتائج

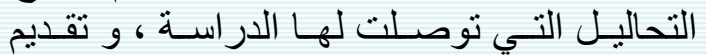

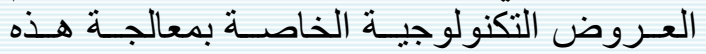

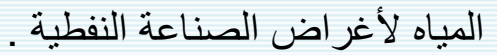

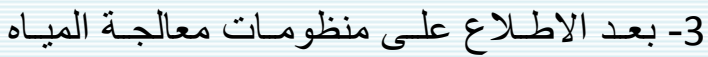

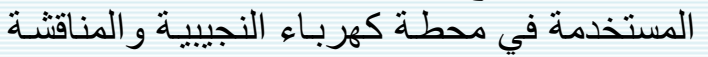

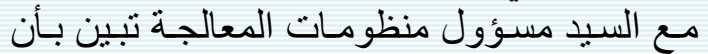
للائرة أعلاه خبرة واسعة في هذا لمات المجال حيث

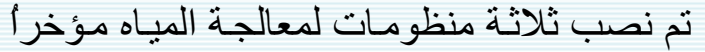

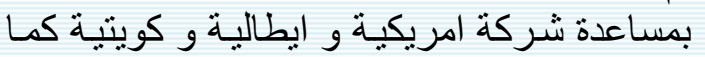
نفذوا مشـروع ام قصـر لتحليـة الميـاه مـن الابـار

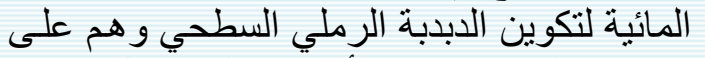

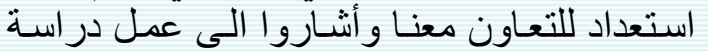

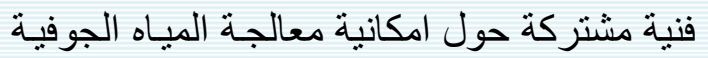

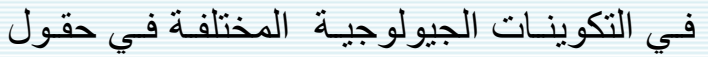

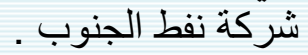
4- اذا كانت النتائج في التوصيات أعلاه ايجابية فنوصي بما بأني : لوان

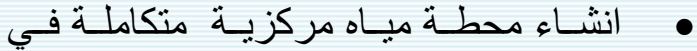

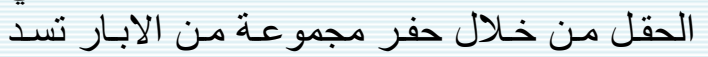

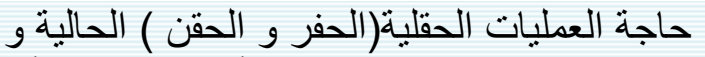

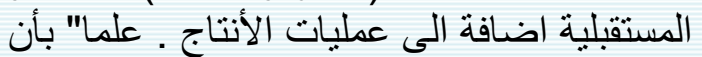

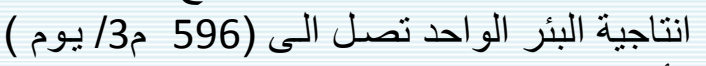

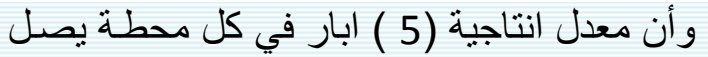

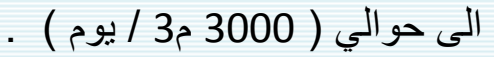

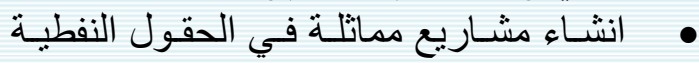
البعيدة عن مصادر المياه التقليدية.

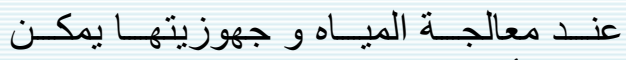

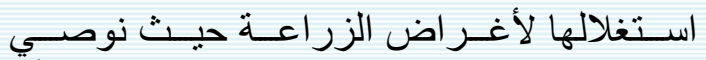

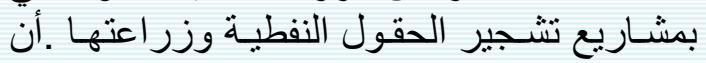

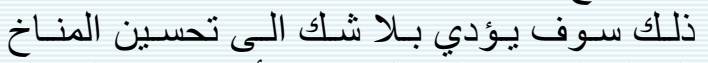

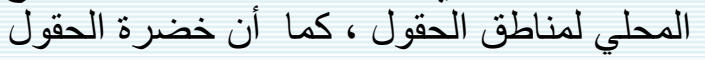

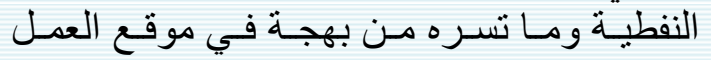

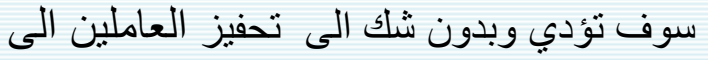

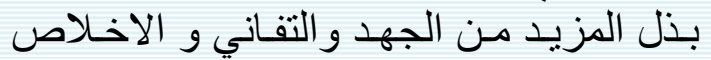

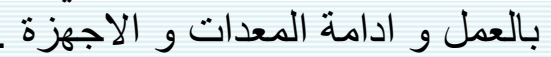

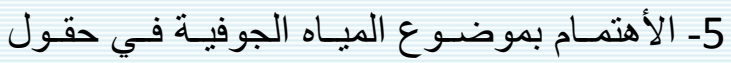

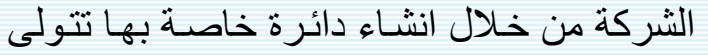

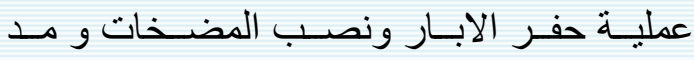

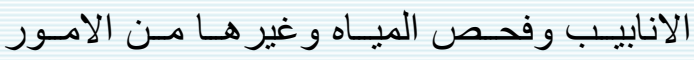

\section{الأستبنابات}

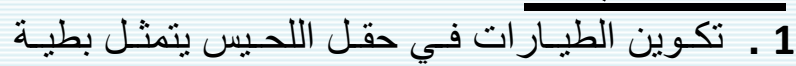

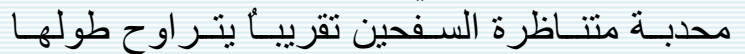

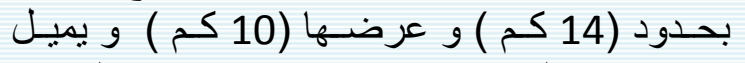

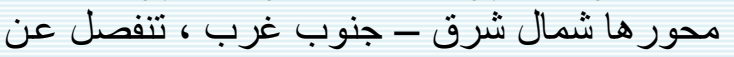

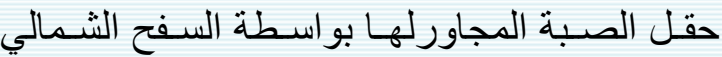

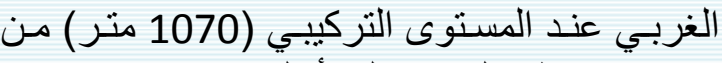

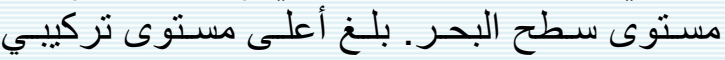

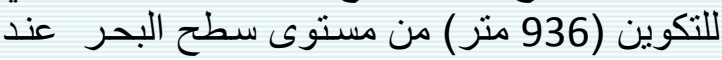

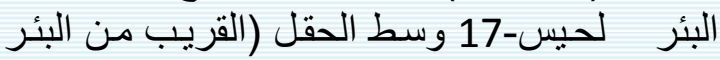

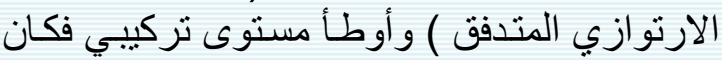

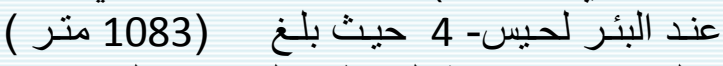

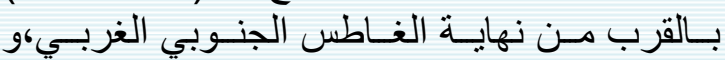

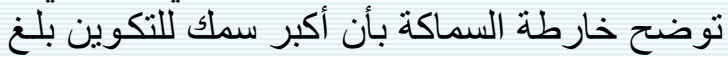

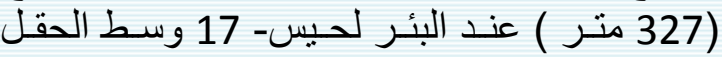

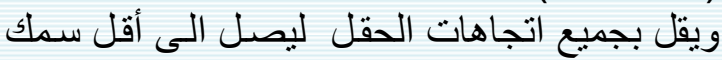
عند البئر لحيس-7 الجيات الجيات

2. تتو اجد المياه الجوفيـة في تكوين الطيارات - حقل حقل

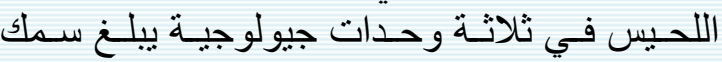

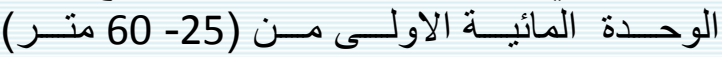

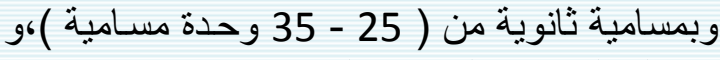

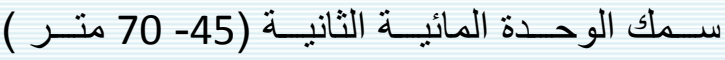

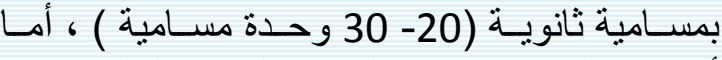

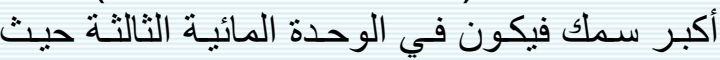

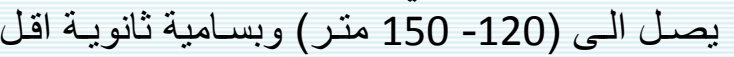

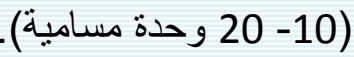

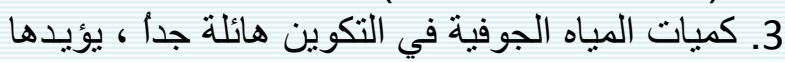

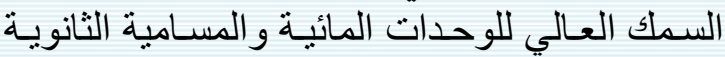

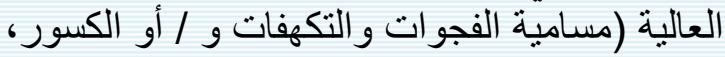

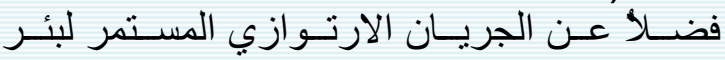

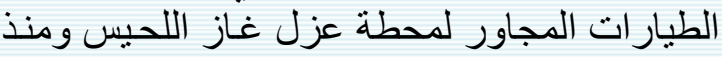

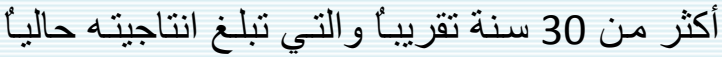

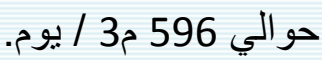

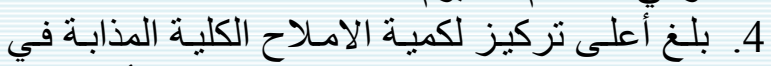

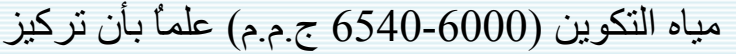
الاملاح الكلية الذائبة في بعض ابـار الميـاه الجوفيـة

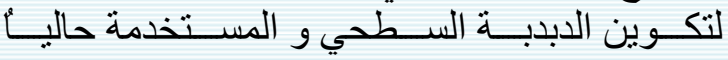

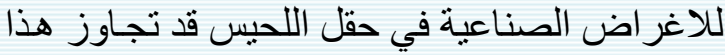

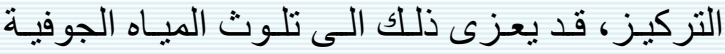

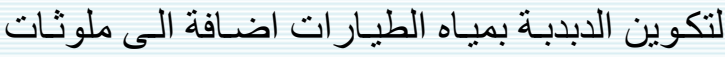

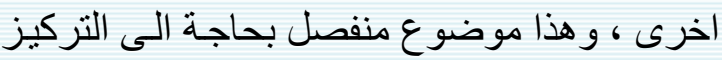

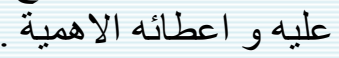

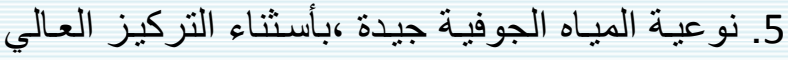

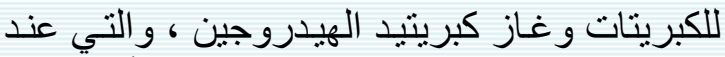

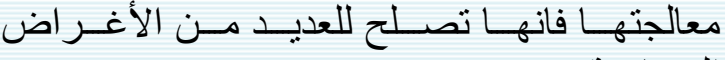




\section{المصـــــادر \\ مواد الدراسة: \\ 1. التقارير الجيولوجية الاولية و النهائية لابار حقل اللحيس. 2. 1قارير الحفر لابار حقل اللحيس. 3. مجسات ابار حقل اللحيس. 4. تحاليل المياه الجوفية القديمة و الحالية.

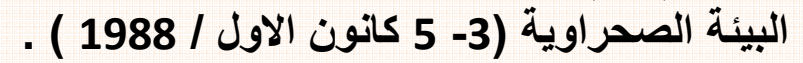

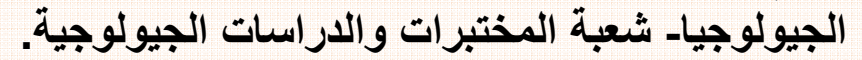

1. عبد.علي.كلي (1988) هايدروجيوكيمياء الموارد المائية في منطقة جنوب غرب العراق.ندوة جيولوجية

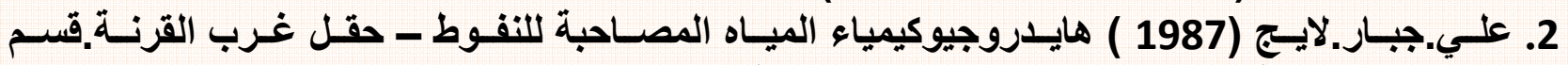

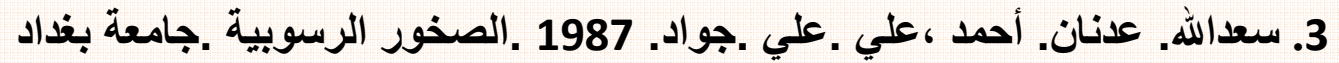

1. Alhassar.1975

2. Aljawzi , A .1976 Tayarat formation ,S.O.C (unpublished report)

3. Buday, T,1980,Regiona geology of iraq, Geological survey and mineral investigation state.Baghdad.

4. Collins, A.G. 1975 Geochemistry of oil field water. Development in petroleum science, 1. Amsterdam - Oxford - New York ,496 p.

5. Davis , S.N. Dewiest , R , J.M. 1966 , Hydrogeology, John Wiley, Inc. N .Y. 436 P.

6. Fuloria , R , C ,1976, Hydrocarbone accumulation in southern iraq . chapt.5 .57$67 p p$.

7. Golds Schmidt.1958,Geochemistry of ground water

8. Hem, J.D .1970,Study and interptetation of the chemical characteristics of natural water( $2^{\text {nd }}$ Ed) U.S.Geol.Surv.Water supply, paper N.1437,363 p.

9. Livinstone.1973, Quality of ground water

10. Stanly N. D . Roger .J . 1966,Hydrogeology, John wiley pub. New York, Chichester.Brisbane.Toronto.96 -152 pp.

11. Sulin V,A.1946,Water of petroleum formations . Moscow,96 P. ( In Russian.)

12. Todd ,D.K. 1963 Ground water hydrology ,John wiley pub. New York,336 p . المواقع الاكترونية:

1.http:// www.arabwater.html

2.http:// www.almyah.net

3.http:// www.wqa.org

4.http:// www.mattson.html 